\title{
The Effect of Laminate Lay-Up on the Multi-Axial Notched Strength of CFRP panels: simulation versus experiment
}

\author{
J L Y Tan, V S Deshpande and N A Fleck*, \\ Cambridge University Engineering Dept., Trumpington St., Cambridge, CB2 1PZ, UK \\ * Corresponding author. Tel.: +44 (0)1223 748240; fax: +44 (0)1223 332662. \\ Email address: naf1@eng.cam.ac.uk
}

21 July 2017

\begin{abstract}
The effect of laminate lay-up upon the evolution of damage and upon the multi-axial failure locus of notched carbon fibre reinforced polymer (CFRP) panels is investigated experimentally and numerically. The proportion of $0^{\circ}$ plies and $\pm 45^{\circ}$ plies is varied, and combined tensile and shear loading (and direct compression) is generated by a modified Arcan test rig. The failure surface is measured for panels containing a central hole or sharp notch, and the evolution of subcritical damage is observed by X-ray $\mathrm{CT}$ and sectioning of the specimens. Three distinct damage modes are evident, depending upon the applied stress state, lay-up and geometry of the stressraiser. The open-hole and open-notch values of tensile and compressive strength increase with the proportion of $0^{\circ}$ plies, whereas the shear strengths do not scale with the proportion of $\pm 45^{\circ}$ plies. Inter-fibre splitting of the main loading bearing plies reduces the stress concentration, but the degree of splitting varies with loading direction and lay-up. The Finite Element (FE) method is used to predict not only damage development within each ply but also inter-ply delamination by the use of cohesive interfaces using a traction-separation law. The predicted failure envelopes and damage evolution are in good agreement with the observations, provided the mesh aligns with the fibre direction. This supports the adopted ply-by-ply FE strategy as a useful predictive tool for composite failure.
\end{abstract}

Key-words: finite element prediction, failure envelope, notched strength, damage development 


\section{Introduction}

The strength of notched fibre composite laminates depends upon material system, lay-up, stress-raiser, loading direction and environment (Awerbuch et al, 1985). In the present study, the notch sensitivity of a carbon fibre reinforced polymer (CFRP) laminate is measured and modelled for loading by combined tension and shear, and also for loading by direct compression. A wide range of lay-ups are considered and competing mechanisms of damage development are reported. The work expands upon a previous experimental study (Tan et al., 2015) and a previous numerical study (Tan et al., 2016) on a single quasi-isotropic lay-up.

Consider, in turn, the notch sensitivity of a CFRP laminate under tensile, compressive and shear loading. First, consider in-plane tension. Eriksson and Aronsson (1990) found that the tensile notch strength increases with increasing proportion of $0^{\circ}$ plies, and, along with Carlsson et al (1989), Chow et al. (1990), O'Higgins et al. (2008), Kortshot and Beaumont (1990) and Laffan et al (2010) they noted that the degree of notch sensitivity correlates inversely with the degree of sub-critical damage development. Kortschot and Beaumont (1990) (and more recently O'Higgins et al., 2008) found that the blocking of plies in a cross-ply laminate increases notched tensile strength but decreases the degree of subcritical damage. Green et al. (2007) observed that the notched tensile strength of quasi-isotropic, sublaminate-scaled specimens decreased with increasing specimen size, whereas the notched tensile strength of quasi-isotropic ply-blocked specimens increased with increasing specimen size. Failure modes comprised pull-out (fibre dominated failure with extensive subcritical damage), brittle behaviour (fibre dominated failure with little subcritical damage) and delamination (matrix dominated failure). The effect of lay-up upon tensile strength of notched tensile specimens has also been modelled. For example, Kortschot and Beaumont (1991) predicted the tensile strength by considering the growth of subcritical damage ( $0^{\circ}$ split length) for a range of cross-ply CFRP laminates. Li et al. (2012) and Hallett et al. (2009) used finite elements and cohesive zones to model the development of inter-ply delamination and intra-ply splits.

Second, consider in-plane compression of a notched laminate. The dominant damage and critical failure mechanism is plastic microbuckling of the $0^{\circ}$ plies. The presence of $\pm 45^{\circ}$ plies reduces the notch sensitivity of compressive specimens through more extensive damage (Soutis et al., 1993), and the sensitivity of compressive strength to lay-up has been predicted by taking into account the unnotched compressive strength and fracture toughness of the laminate (Soutis, 1994; Berbinau et al, 1999). 
Third, consider the shear case. Hollmann (1991) and Zhou et al. (1995) found that the inplane notched shear strength was strongly dependent on the number of $\pm 45^{\circ}$ plies. But there remains a clear gap in the literature on the systematic characterisation of progressive shear damage in notched multi-directional CFRP laminates. Preliminary attempts to characterise damage and failure in notched CFRP laminates under combined tension and shear was conducted by Gning et al. (2010) and Laffan et al. (2010). However, Gning et al. (2010) limited their study to visual inspection while Laffan et al. (2010) examined the fracture surfaces. The characterisation of damage evolution in fibre composites for combined tension and shear remains to be addressed, by building upon the response of a quasi-isotropic laminate in two companion papers (Tan et al., 2015; Tan et al., 2016)

In the present study, the multi-axial failure envelope of notched laminates (sharp notch and circular hole) is measured for a $0^{\circ}$ ply-dominated lay-up, a $\pm 45^{\circ}$ ply-dominated lay-up and a crossply lay-up, and measurements are compared with previous results of Tan et al. (2015) for a quasiisotropic lay-up. Finite element predictions of the failure envelope and evolution of damage are used to obtain additional insight.

\section{Test Method}

HexPly ${ }^{\circledR}$ IM7/8552 CFRP laminates were hand laid-up to the specification in Table 1 and were autoclaved according to the manufacturer's cure cycle. Four lay-ups were manufactured: $0^{\circ}$ ply-dominated (0dom), $\pm 45^{\circ}$ ply dominated (45dom) and cross-ply (CP), with the results for a quasi-isotropic (QI) lay-up taken from Tan et al. (2015). All lay-ups comprised 16 plies, resulting in a laminate thickness of $2 \mathrm{~mm}$, except for the 15-ply cross-ply lay-up (CP) of thickness $1.875 \mathrm{~mm}$. The as-cured CFRP panels were cut into specimens of dimension $90 \mathrm{~mm} \times 25 \mathrm{~mm}$ using a water-cooled diamond saw. The specimens were then end-tabbed with $1.0 \mathrm{~mm}$ thick aluminium sheet using a toughened epoxy adhesive (Spabond 345), to give a gauge section of length $23 \mathrm{~mm}$ (and width $w=25 \mathrm{~mm}$ ), see Fig. 1a. Two geometries of stress-raiser were employed: (i) a circular hole of diameter $6 \mathrm{~mm}$, machined using a tungsten carbide drill bit; and (ii) a notch of height $b=0.70 \mathrm{~mm}$ (root radius $0.35 \mathrm{~mm}$ ) and length $a=6.25 \mathrm{~mm}$. To achieve this, a linear array of small holes was joined using a fine fretsaw blade. Any minor misalignment from hole to hole of the array has a negligible influence upon the strength of the specimen, as discussed in Tan et al. (2015). 
The specimens were loaded at a rate of $0.01 \mathrm{mms}^{-1}$ in tension, compression, shear, or in combined tension and shear using a modified Arcan rig assembly, see Fig. 1b. The modified Arcan rig is capable of applying loads at loading angle $\varphi$ in intervals of $15^{\circ}$. When $\varphi$ equals $0^{\circ}$, the loading is tension or compression depending upon the loading direction. When $\varphi$ equals $90^{\circ}$, the loading is simple shear. An intermediate angle $\varphi$ between $0^{\circ}$ and $90^{\circ}$ gives tension and shear. If the applied load is $P$, then the tensile component of load equals $P \cos \varphi$ and the shear component equals $P \sin \varphi$. Thus, the ratio of shear traction to normal traction on the specimen is given by $\tau / \sigma=\tan \varphi$.

Specimens were loaded to failure in order to determine the net-section failure strength, and interrupted tests were then performed on selected specimens to observe the subcritical damage evolution. A combination of penetrant-enhanced X-ray CT and microscopy on de-plied specimens aided the ply-by-ply (and inter-ply) damage visualisation. Full details of the loading method (modified Arcan rig) and the damage visualisation techniques can be found in Tan et al. (2015).

\section{Finite Element Model}

The ABAQUS-based FE model of Tan et al. (2016) was extended in this study to assess its accuracy for a wide range of lay-ups. Each ply was modelled using a single layer of 8-noded reduced-integration continuum shell elements (SC8R). Delaminaton between adjacent plies was modelled using a single layer of cohesive elements (COH3D8): these cohesive elements enabled the specification of a traction versus separation law between plies. The mesh density was greatest at the stress raiser in order to capture the elastic stress concentration factor; to achieve this, the smallest element was of side length $50 \mu \mathrm{m}$. Here we briefly explain the constitutive model for each ply and the cohesive model used to capture delamination.

\subsection{Brief description of the constitutive model}

Consider a single ply of a fibre-reinforced unidirectional laminate with the $x_{1}$ axis in the fibre direction, $x_{2}$ in the transverse direction and $x_{3}$ perpendicular to the plane of the ply. The unidirectional ply is transversely isotropic with respect to the fibre direction (i.e. $x_{1}$ axis). For a 
state of plane stress $\left(\sigma_{33}=\sigma_{32}=\sigma_{13}=0\right.$ ), the elastic response of the undamaged material is given by

$$
\left(\begin{array}{l}
\varepsilon_{11} \\
\varepsilon_{22} \\
\gamma_{12}
\end{array}\right)=\left(\begin{array}{ccc}
1 / E_{1} & -v_{21} / E_{1} & 0 \\
-v_{12} / E_{2} & 1 / E_{2} & 0 \\
0 & 0 & 1 / G
\end{array}\right)\left(\begin{array}{l}
\sigma_{11} \\
\sigma_{22} \\
\sigma_{12}
\end{array}\right)
$$

where $\varepsilon_{11}$ and $\varepsilon_{22}$ are the direct strains in the $x_{1}$ and $x_{2}$ directions, respectively, while $\gamma_{12}$ is the engineering shear strain. The Young's moduli $E_{1}$ and $E_{2}$ in the $x_{1}$ and $x_{2}$ directions, along with the shear modulus $G$ and Poisson's ratio $v_{21}$, are the four relevant elastic constants of the unidirectional laminate in this plane stress state.

\section{The damage law}

The laminate is taken to be linear elastic as specified by Eq. (3.1) up to the initiation of damage. A non-linear stress versus strain response accompanies damage progression, due to a progressive drop in the three moduli $\left(E_{1}, E_{2}, G\right)$ with increasing strain. Four scalar damage variables are introduced, corresponding to four damage modes (tensile and compressive failure in each of the fibre and transverse directions). In the undamaged state each damage variable is set to zero. As strain-controlled damage accumulates, one or more damage variables increases to a maximum value of unity. The moduli drop with increasing value of the damage variables, such that one or more moduli equal zero when one of the damage variables attains unity.

The damage model comprises two steps. First, damage can accumulate when a critical strain state is attained as proposed by Hashin (1980), and this condition is usually re-expressed in terms of the associated critical stress state. This is similar to the yield surface in plasticity theory: for a stress state within the damage locus, no additional damage occurs and the stress versus strain response is linear and reversible. Second, the damage variable(s) increase non-linearly with increasing strain and this leads to a drop in moduli and thereby to a drop in stress. The damage evolution law follows that laid down by Matzenmiller et al. (1995).

Denote the tensile and compressive strengths for damage initiation in the undamaged laminate and in the fibre direction $\left(x_{1}\right.$-direction) by $X^{T}$ and $X^{c}$, respectively. The corresponding tensile and compressive strengths in the transverse direction are denoted by $Y^{T}$ and $Y^{c}$, 
respectively. After damage has developed these strengths drop as follows. Write the damage variable for tensile failure in the fibre direction as $d_{f}^{t}$. Then, the current tensile strength in the fibre direction is $\left(1-d_{f}^{t}\right) X^{T}$. Likewise, the damage variables for compressive loading in the fibre direction is $d_{f}^{c}$, while that for transverse tension and compression is $d_{m}^{t}$ and $d_{m}^{c}$, respectively. No additional damage develops when the stress state lies within the following critical surfaces of Hashin (1980):

$$
\begin{gathered}
\frac{\left\langle\sigma_{11}\right\rangle}{\left(1-d_{f}^{t}\right) X^{T}}<1 \\
\frac{\left\langle-\sigma_{11}\right\rangle}{\left(1-d_{f}^{c}\right) X^{c}}<1 \\
\left(\frac{\left\langle{ }_{22}\right\rangle}{\left(1 d_{m}^{t}\right) Y^{T}}\right)^{2}+\left(\frac{2 d_{12}}{\left(\begin{array}{ll}
1 & d_{s}
\end{array}\right) Y^{T}}\right)^{2}<1
\end{gathered}
$$

and

$$
\left(\frac{\left\langle{ }_{22}\right\rangle}{\left(1 d_{m}^{c}\right) Y^{c}}\right)^{2}+\left(\frac{2{ }_{12}}{\left(1 d_{s}\right) Y^{c}}\right)^{2}<1
$$

where \langle\rangle represents the Macaulay bracket of value zero when its argument is negative. The shear damage $d_{s}$ is defined as

$$
d_{s} \equiv 1-\left(1-d_{f}^{t}\right)\left(1-d_{f}^{c}\right)\left(1-d_{m}^{t}\right)\left(1-d_{m}^{c}\right)
$$

In any given state of damage, the secant relationship between stress and strain reads

$$
\left(\begin{array}{l}
\varepsilon_{11} \\
\varepsilon_{22} \\
\gamma_{12}
\end{array}\right)=\left(\begin{array}{ccc}
1 /\left[E_{1}\left(1-d_{f}\right)\right] & -v_{21} /\left[E_{1}\left(1-d_{f}\right)\right] & 0 \\
-v_{12} /\left[E_{2}\left(1-d_{m}\right)\right] & 1 /\left[E_{2}\left(1-d_{m}\right)\right] & 0 \\
0 & 0 & 1 /\left[G\left(1-d_{s}\right)\right]
\end{array}\right)\left(\begin{array}{l}
\sigma_{11} \\
\sigma_{22} \\
\sigma_{12}
\end{array}\right)
$$

where 


$$
\begin{aligned}
& d_{f}= \begin{cases}d_{f}^{t} & \text { if } \sigma_{11} \geq 0 \\
d_{f}^{c} & \text { otherwise }\end{cases} \\
& \text { and } \\
& d_{m}= \begin{cases}d_{m}^{t} & \text { if } \sigma_{22} \geq 0 \\
d_{m}^{c} & \text { otherwise }\end{cases}
\end{aligned}
$$

We note from Eqs. (3.7) and (3.8) that if the composite is fully damaged in say the compressive fibre damage mode, it can still sustain tensile fibre stresses. The validity of this assumption remains to be verified experimentally.

The evolution law is now summarised for each of the four independent damage variables $d_{f}^{t}, d_{f}^{c}, d_{m}^{t}$ and $d_{m}^{c}$. The damage growth law adopted here is based upon the assumption that the stress decreases linearly with increasing strain once damage initiates. First, consider the tensile fibre damage mode. An effective fibre strain $\hat{\varepsilon}_{f}^{t}$ is defined as $\hat{\varepsilon}_{f}^{t} \equiv\left\langle\varepsilon_{11}\right\rangle$ and is used to update the damage state variable via the relation

$$
d_{f}^{t}=\frac{\frac{2 J_{f}^{t}}{L_{e} X^{T}}\left(\hat{\varepsilon}_{f}^{t}-X^{T} / E_{1}\right)}{\hat{\varepsilon}_{f}^{t}\left(\frac{2 J_{f}^{t}}{L_{e} X^{T}}-X^{T} / E_{1}\right)} \leq 1
$$

where $X^{T} / E_{1}$ is the value of $\hat{\varepsilon}_{f}^{t}$ when tensile fibre first initiates and $\frac{2 J_{f}^{t}}{L_{e} X^{T}}$ is the strain for complete tensile fibre damage for any assumed element size $L_{e}$. Here, $J_{f}^{t}$ is the tensile fibre fracture energy and it is dissipated within the element that fails. We note in passing that an additional constraint must be imposed upon (3.9) for it to be meaningful: $\dot{d}_{f}^{t} \geq 0$, reflecting that fact that damage is not healed. When the axial strain is decreased we hold $d_{f}^{t}$ fixed.

Similarly, the compressive fibre damage variable is specified as

$$
d_{f}^{c}=\frac{\frac{2 J_{f}^{c}}{L_{e} X^{c}}\left(\hat{\varepsilon}_{f}^{c}-X^{c} / E_{1}\right)}{\hat{\varepsilon}_{f}^{c}\left(\frac{2 J_{f}^{c}}{L_{e} X^{c}}-X^{c} / E_{1}\right)} \leq 1
$$


where $J_{f}^{c}$ is the compressive fibre fracture energy and the effective strain is $\hat{\varepsilon}_{f}^{c} \equiv\left\langle-\varepsilon_{11}\right\rangle$. The matrix damage variables are given by

$$
d_{m}^{t}=\frac{\frac{2 J_{m}^{t}}{L_{e} Y^{T}}\left(\hat{\varepsilon}_{m}^{t}-Y^{T} / E_{2}\right)}{\hat{\varepsilon}_{m}^{t}\left(\frac{2 J_{m}^{t}}{L_{e} Y^{T}}-Y^{T} / E_{2}\right)} \leq 1
$$

and

$$
d_{m}^{c}=\frac{\frac{2 J_{m}^{c}}{L_{e} Y^{c}}\left(\hat{\varepsilon}_{m}^{c}-Y^{c} / E_{2}\right)}{\hat{\varepsilon}_{m}^{c}\left(\frac{2 J_{m}^{c}}{L_{e} Y^{c}}-Y^{c} / E_{2}\right)} \leq 1
$$

where $J_{m}^{c}$ and $J_{m}^{t}$ are the matrix compressive and tensile fracture energies, respectively and the effective strains are defined as $\hat{\varepsilon}_{m}^{t} \equiv \sqrt{\left\langle\varepsilon_{22}\right\rangle^{2}+\varepsilon_{12}^{2}}$ and $\hat{\varepsilon}_{m}^{c} \equiv \sqrt{\left\langle-\varepsilon_{22}\right\rangle^{2}+\varepsilon_{12}^{2}}$. In this study, we choose $L_{e}$ to be the size of a finite element; numerical experimentation confirmed that this choice gives a response which is almost independent of mesh size. The material parameters required for this constitutive description of the ply are listed in Table 2, based on calibrations performed by Tan et al. (2016).

\subsection{Cohesive model for the interface between plies}

The unidirectional plies were attached to each other via a cohesive layer. This cohesive surface simulates the traction versus separation behaviour of the plies and permits the FE model to include possible delamination of the plies. Define the normal traction between the plies as $t_{n}$ and the two shear tractions as $t_{t}$ and $t_{s}$. The corresponding normal and shear separations are denoted by $\delta_{n}, \delta_{t}$ and $\delta_{s}$. The cohesive relationship is defined in two steps: (i) the undamaged traction-separation relation and (ii) a softening relation after the onset of damage.

At any given instant, the traction versus separation relation is of the form 


$$
\begin{aligned}
t_{n} & = \begin{cases}(1-D) k_{n} \delta_{n} & \delta_{n}>0 \\
k_{n} \delta_{n} & \text { otherwise }\end{cases} \\
t_{s} & =(1-D) k_{s} \delta_{s} \\
t_{t} & =(1-D) k_{s} \delta_{t}
\end{aligned}
$$

where $k_{n}$ and $k_{s}$ are the normal and shear stiffnesses, respectively, and the damage variable $D$ satisfies $0 \leq D \leq 1$. Note that damage does not affect the cohesive relation when $\delta_{n} \leq 0$, i.e. in compression the interaction between two plies reduces to a penalty contact algorithm. In the undamaged state (at the beginning of the calculation) the damage variable $D=0$ and no additional damage develops when the traction state lies within the following surface

$$
\left[\frac{\left\langle t_{n}\right\rangle}{(1-D) T_{n}}\right]^{2}+\left[\frac{t_{s}}{(1-D) T_{s}}\right]^{2}+\left[\frac{t_{t}}{(1-D) T_{s}}\right]^{2}<1
$$

where $T_{n}$ and $T_{s}$ represent the peak values of the traction when the separation is either purely normal or pure shear, respectively. The evolution law for $D$ is chosen based upon the assumption that the tractions decrease linearly with increasing separation once damage initiates. Define an effective separation

$$
\delta_{e} \equiv \sqrt{\left\langle\delta_{n}\right\rangle^{2}+\delta_{s}^{2}+\delta_{t}^{2}}
$$

The work-conjugate traction to this effective separation is

$$
t_{e} \equiv \sqrt{\left\langle t_{n}\right\rangle^{2}+t_{s}^{2}+t_{t}^{2}}
$$

The damage variable $D$ is then defined in terms of an effective fracture energy $G_{c}$ as

$$
D=\frac{\frac{2 G_{c}}{t_{e}^{0}}\left(\delta_{e}^{\max }-\delta_{e}^{0}\right)}{\delta_{e}^{\max }\left(\frac{2 G_{c}}{t_{e}^{0}}-\delta_{e}^{0}\right)} \leq 1
$$

where $\delta_{e}^{\max }$ is the maximum value of $\delta_{e}$ attained during the loading history while $t_{e}^{0}$ and $\delta_{e}^{0}$ are the values of the effective traction and separation at the initiation of damage. The effective fracture energy is defined in terms of the normal fracture energy $G_{c}^{n}$ and shear fracture energy $G_{c}^{s}$; see the ABAQUS user manual for additional details. The material parameters that define the interface model are thus the stiffnesses $k_{n}$ and $k_{t}$, maximum tractions $T_{n}$ and $T_{s}$ as well as the fracture energies $G_{c}^{n}$ and $G_{c}^{s}$. The values of these six parameters used in the numerical calculations presented here are listed in Table 3 as calibrated by Tan et al. (2016). 
The FE model was used to predict the net-section strength, failure envelope, subcritical damage evolution and critical failure mechanisms for the laminate lay-ups under tension-shear and compression-shear. Both notch and circular hole specimen geometries were modelled. The predictions are compared against the experimental data to assess the capabilities of the numerical approach.

\section{Experimental Results}

\subsection{Failure Envelopes}

All specimen configurations failed from the central stress raiser. All lay-ups except for the CP lay-up failed in combined tension and shear by catastrophic fibre failure. In contrast, the CP laminate was matrix-governed under macroscopic shear, and failed in a graceful fashion (via a series of load drops) by a combination of intra-ply splitting and inter-ply delamination. Consequently, the CP lay-up was excluded from the combined tension and shear study.

The application of macroscopic tension to the notch or hole specimens, of the lay-ups QI, 0dom and 45dom, led to tensile failure and splitting of the $0^{\circ}$ plies, as sketched in Fig. 2. This is termed 'Mechanism A', and the superposition of a low level of macroscopic shear stress had only a minor effect: the splitting mode became asymmetric as shown in Fig. 2 for the choice $\varphi=15^{\circ}$. Now consider the application of macroscopic shear $\left(=90^{\circ}\right)$ to the notched lay-ups QI, Odom and $45 \mathrm{dom}$. Failure is dictated by tensile failure of the main load-bearing $-45^{\circ}$ plies, with attendant splitting as sketched in Fig. 2, and termed 'Mechanism B'. The superposition of remote tension such that $\varphi<90^{\circ}$ has only a minor effect upon the qualitative details of this failure mode. Now consider direct compression, $\varphi=180^{\circ}$, which gives rise to fibre microbuckling from the edge of the stress raiser; this is termed 'Mechanism C'.

The net-section strength of each lay-up and notch geometry are calculated from the measured peak loads, and the average values are plotted in tension-shear stress space, see Fig. 3. The dominant regime of each failure mechanism is indicated by the following markers: Mechanism A by triangles, Mechanism B by circles, and Mechanism C by squares.

For the specimens with a sharp notch or an open hole, the loading angle $\varphi_{t}$ at which Mechanism A transitions into Mechanism B reduces with increasing proportions of $0^{\circ}$ plies: $\varphi_{t}$ 
equals approximately $15^{\circ}$ for the Odom lay-up, $30^{\circ}$ for the QI lay-up and $45^{\circ}$ for the 45 dom lay-up as shown in Fig. 3a. The interaction between the competing mechanisms (Mechanisms A and B) is much more pronounced for the circular hole specimens. The explanation lies in the relative extent of subcritical damage, as discussed by Tan et al. $(2015,2016)$.

The role of stress concentration upon failure strength can be ascertained by comparing the failure envelopes for the sharp notch in Fig. $3 \mathrm{a}$ with those for the circular hole, Fig. 3b. The failure envelope of the QI notch specimen lies outside that of the circular hole specimen, whereas the net-section strengths are comparable for the 0dom notch and hole geometries for all stress states investigated: the failure envelopes overlap each other. Now consider the net-section strengths for Mechanism B in the 45dom lay-up; the notch specimen is stronger than the hole specimen. In contrast, the strengths for Mechanisms $\mathrm{A}$ and $\mathrm{C}$ are independent of notch acuity. Interrupted tests reported below reveal that these results are consistent with the degree of splitting induced at the notch tips in the load-bearing plies: the more extensive the splits, the stronger is the specimen.

\subsection{Notch Strength as a function of lay-up}

The proportion of $0^{\circ}$ and $\pm 45^{\circ}$ plies varies from lay-up to lay-up, and it is expected that the tensile and compressive strengths will increase with increasing proportion of $0^{\circ}$ plies, while the shear strength will increase with the proportion of $\pm 45^{\circ}$ plies. To assess this, the notch strength and open hole strength are plotted as a function of ply content in Figs. 4 to 6 . Tension $\left(\varphi=0^{\circ}\right)$ results in the activation of Mechanism A, see Fig. 4, shear $\left(\varphi=90^{\circ}\right)$ activates Mechanism B, see Fig. 5, and compression $\left(\varphi=180^{\circ}\right)$ results in failure by Mechanism C, see Fig. 6. The net-section tensile strength for the notch and hole cases scale almost linearly with the proportion of loadbearing $0^{\circ}$ plies in the laminates, see Fig. 4. Similarly, the compressive strengths scale with the proportion of load-bearing $0^{\circ}$ plies, recall Fig. 6 . In contrast, the net-section shear strength is only mildly sensitive to the proportion of $\pm 45^{\circ}$ plies in Fig. 5, despite the fact that Mechanism B involves microbuckling of the $-45^{\circ}$ plies. An explanation for these features is provided below with reference to the relative degree of damage development as a function of ply lay-up. In order to simplify comparisons between the damage and failure exhibited by each lay-up, the discussion on Mechanism A is limited to the tension case $\left(\varphi=0^{\circ}\right)$, discussion on Mechanism B to the shear case $\left(\varphi=90^{\circ}\right)$, and discussion on Mechanism $C$ to the compression case $\left(\varphi=180^{\circ}\right)$. We shall first 
discuss Mechanisms $\mathrm{A}$ and $\mathrm{C}$ with reference to Fig. 7, as they have some similarities in damage mode (failure and splitting of $0^{\circ}$ plies), and then discuss Mechanism B with reference to Fig. 8 .

Mechanism A: The dominant damage and critical failure mechanisms associated with Mechanism A occur in the load-bearing $0^{\circ}$ plies of the laminate, as exemplified in Fig. 7a by the X-ray CT-scans of the $0^{\circ}$ plies of each lay-up at $90 \%$ tensile failure load. Two damage mechanisms exist in the $0^{\circ}$ ply orientation for all the lay-ups: $0^{\circ}$ splits and $0^{\circ}$ fibre tensile fracture, recall Fig. 2 . The $0^{\circ}$ splits blunt the notch by redistributing the tensile stress in the fibre direction ahead of the notch tip. The length $l_{s}$ of the $0^{\circ}$ splits at $90 \%$ tensile failure load increase with the proportion of $0^{\circ}$ plies, whereas the length $l_{f}$ of the $0^{\circ}$ fibre crack increases with increasing fraction of $\pm 45^{\circ}$ plies (and thereby decreasing proportion of $0^{\circ}$ plies), see Fig. $7 \mathrm{~b}$.

Mechanism C: The dominant damage and critical failure mechanism associated with Mechanism $\mathrm{C}$ is microbuckling of the load-bearing $0^{\circ}$ fibres. X-ray CT-scans of the $0^{\circ}$ plies of each lay-up at $90 \%$ of the compressive failure load are given in Fig. 7c, indicating that the extent of subcritical microbuckling of the $0^{\circ}$ fibres decreases with increasing proportion of $0^{\circ}$ plies. $0^{\circ}$ splits are also evident, particularly in the 0dom lay-up. As for the tensile case, the $0^{\circ}$ split length $l_{s}$ increases with the proportion of $0^{\circ}$ plies, whereas the microbuckle lengths $l_{m}$ diminish with the proportion of $0^{\circ}$ plies, see Fig. $7 \mathrm{~d}$. The splits are significantly shorter and the damage directly ahead of the notch longer for Mechanism C than for Mechanism A, compare Figs. 7d and b.

Mechanism B: Recall that the dominant damage and critical failure mechanisms associated with the shear Mechanism B occur in the $-45^{\circ}$ ply orientation, as sketched in Fig. 2. Xray CT-scans of the $-45^{\circ}$ plies of each lay-up at $90 \%$ shear failure load are given in Fig. 8. All layups exhibited stable microbuckle growth and splitting at the notch tips in the $-45^{\circ}$ plies prior to failure. Failure was by microbuckling of the load-bearing $-45^{\circ}$ plies, but the direction and extent of microbuckling within the $-45^{\circ}$ plies is dependent on lay-up. The 0dom lay-up experiences the growth of two microbuckle bands from the notch tips, whereas a single microbuckle band propagates in the QI and 45dom lay-ups prior to ultimate failure. The microbuckle length at $90 \%$ failure load is sensitive to lay-up, with the 45dom lay-up having the shortest length. These differences in microbuckle growth are a consequence of the difference in material orthotropy (as given by laminate plate theory). Splits within plies adjacent to the $-45^{\circ}$ ply also have a significant influence in guiding the stable progression of the microbuckles (Tan et al, 2015). Since each layup has a different orientation of adjacent ply to the $-45^{\circ}$ ply, the effect of splits in adjacent plies 
may be significant. The finite element analysis below is used to explore this hypothesis. An explicit comparison of the evolution of microbuckle length and split length is omitted in Fig. 8 due to the complex nature of the microbuckle arrangement from specimen lay-up to lay-up.

\section{Numerical Results}

The capabilities of the FE model for predicting damage development and the failure locus of the 0dom, 45dom and CP lay-ups are now assessed. An assessment for the QI specimens has already been given in Tan et al. (2016). All FE simulations were performed using the explicit version of ABAQUS (version 6.12) to give converged quasi-static solutions.

A comparison of the predicted and measured failure envelopes for both the notch and circular hole specimens are given in Fig. 9a,b for the 0dom lay-up, and in Fig. 9c,d for the 45dom lay-up. In broad terms, the FE model accurately predicts the failure envelopes of the Odom specimens, with somewhat less accuracy for the $45 \mathrm{dom}$ specimens. The FE model is conservative for the 45dom lay-up and correctly predicts that the notch specimens are stronger than the circular hole specimens for Mechanism B, compare Figs. 9c and d. The reason for the reduced fidelity of the predictions for splits in the 45 plies is traced to the topology of the mesh. The mesh was aligned with the 0 and 90 fibre directions, and splits in these directions are not impeded by the mesh boundaries, as discussed extensively by González and co-workers (González et al, 2012; Lopes et al., 2016). In contrast, the mesh in the 45 plies did not align with the local fibre direction and consequently the prediction of splitting of these plies is less accurate.

The capabilities of the FE model in simulating the observed subcritical damage in the various lay-ups is now assessed. We attempt to correlate the combined damage parameter $d$ (as defined in Eq. (3.6)) with the experimentally observed damage. As the model has already been shown to produce adequate predictions of damage for the QI lay-up (Tan et al. 2016), results for the other lay-ups (0dom, 45dom and CP) are now discussed. The main comparisons are limited to tension (representative of Mechanism A), shear (Mechanism B) and compression (Mechanism C). Results are presented primarily for the notch configuration as damage development is qualitatively similar for the hole configuration. Since the extent of damage induced by the notch is generally larger than for the circular hole, observation of damage is made easier for the notch.

Mechanism A: The predicted and measured $0^{\circ}$ ply damage in the various lay-ups at $90 \%$ of their respective tensile failure loads are given in Fig. 10 for remote tension. Accurate simulations of 
subcritical damage are obtained for the $45 \mathrm{dom}$ and 0dom lay-ups. In particular, the short $0^{\circ}$ splits and significant fibre tensile fracture at the notch tips of the $45 \mathrm{dom}$ specimens are captured by the FE model. The model also predicts the extensive $0^{\circ}$ splits in the 0dom laminate. However, the $0^{\circ}$ splits in the CP lay-up are over-predicted by the FE model. Recalling the effect of $0^{\circ}$ splitting on tensile strength, this result explains why the tensile strength of the CP lay-up is over-predicted by the model.

Mechanism B: A comparison of the predicted and measured $-45^{\circ}$ ply damage in the 0dom and 45dom lay-ups at $90 \%$ of their respective shear failure loads is given in Fig. 11. The FE model predicts microbuckling in both lay-ups but under-predicts the degree of splitting of the $-45^{\circ}$ plies. Matrix failure was predicted in the localised regions where $-45^{\circ}$ splits grow but it did not extend progressively along the direction of the $-45^{\circ}$ splits as observed in the experiments. Nevertheless, the model yields adequate predictions of shear strength for the 45 dom lay-up.

Mechanism C: A comparison of the predicted and measured $0^{\circ}$ ply damage in the various lay-ups at $90 \%$ of their respective compressive failure loads is given in Fig. 12. Experiments revealed that the 45dom lay-up exhibited the most extensive microbuckles of all the lay-ups at $90 \%$ failure load, while the Odom lay-up and CP lay-up exhibited small amounts of microbuckling. The FE model accurately captures the extent of microbuckling in each lay-up. However, the FE model was unable to predict the occurrence of $0^{\circ}$ splits, particularly in the 0dom lay-up; consequently, the model under-predicts the notch strength.

Some representative results for the circular hole specimens are now reported to further demonstrate the capabilities of the model in predicting damage. A comparison between predicted and measured damage state is given in Fig. 13 for three examples, each at $90 \%$ of their respective failure loads: $0^{\circ}$ ply damage in the 0 dom laminate under pure tension $\left(\varphi=0^{\circ}\right.$, Mechanism A); $45^{\circ}$ ply damage in the $45 \mathrm{dom}$ laminate under pure shear $\left(\varphi=90^{\circ}\right.$, Mechanism B $)$; and $0^{\circ}$ ply damage in the CP laminate under pure compression $\left(\varphi=180^{\circ}\right.$, Mechanism C). The model correctly predicts the main damage mechanisms in each case: (i) extensive $0^{\circ}$ splits in the 0dom laminate (Mechanism A), (ii) microbuckles that propagate in the $-45^{\circ}$ plies of the $45 \mathrm{dom}$ laminate (Mechanism B), and (iii) microbuckles in the $0^{\circ}$ plies of the CP laminate (Mechanism C).

\section{Discussion}


All lay-ups exhibited the main features associated with Mechanisms A, B and C, as reported in the literature in the following manner. The inter-fibre splits and $0^{\circ}$ fibre fractures in Mechanism A accompany composite tensile fracture (Carlsson et al. , 1989; O'Higgins et al., 2008; Kortschot and Beaumont, 1990; Hallett et al., 2009; Bishop, 1985; Garg, 1986; Wang et al, 2004; Scott et al., 2011; Sket et al., 2012; Xu et al., 2014). In similar fashion, the splits and compressive failure in the $-45^{\circ}$ plies for Mechanism B correspond with the findings of Hollmann (1991) who tested notched laminates in shear. And $0^{\circ}$ fibre microbuckling and splits in Mechanism $\mathrm{C}$ are recognised in the literature on compressive failure (Soutis et al., 1993; Soutis (1994); Fleck, 1997; Sivashanker et al., 1996).

The trends in notched strength as a function of lay-up for Mechanisms A, B and C are also consistent with the available literature. Eriksson and Aronsson (1990) reported that specimens with a larger proportion of $0^{\circ}$ plies have higher tensile strengths, lower notch sensitivities and exhibit more extensive damage. These trends are evident in the results for Mechanism A: the tensile strength scales with the proportion of $0^{\circ}$ plies (see Fig. 4), and the $0^{\circ}$ split length increases with the proportion of $0^{\circ}$ plies (refer to Figure 7a). Kortschot and Beaumont (1990) likewise suggest that the tensile strength of notched specimens is increased by the presence of long $0^{\circ}$ splits. Our results support this claim insofar as laminates with higher proportions of $0^{\circ}$ plies have longer $0^{\circ}$ splits prior to failure (Figure 11) and fail at higher stresses (Figure 5). However, we find that the notch sensitivity of tensile specimens is almost independent of lay-up (compare Figs. 2a and b ), despite there being a large difference in $0^{\circ}$ split lengths across all layups (see Figs. 10 and 13). This demonstrates that split length alone does not dictate the notchblunting effect and that it is insufficient to to assess the degree of notch-blunting solely on the basis of split length.

Our study reveals that the shear failure strength for Mechanism B does not scale with the proportion of $\pm 45^{\circ}$ plies, see Figure 5. This is seemingly at odds with Hollmann (1991) and Zhou et al. (1995), who claim that the shear strength increases with the proportion of $\pm 45^{\circ}$ plies. However, Hollmann (1991) asserted that it is the unnotched shear strength that is strongly influenced by the amount of $\pm 45^{\circ}$ plies (in accordance with our results). Zhou et al. (1995) compared the notched shear strengths of unidirectional, cross-ply and quasi-isotropic lay-ups, and concluded that the in-plane shear strength increases with the number of $\pm 45^{\circ}$ fibres. However, two of the above three lay-ups do not contain $\pm 45^{\circ}$ plies and hence our study does not inform the sensitivity of shear strength to the number of $\pm 45^{\circ}$ plies. 
For the case of pure compression (Mechanism C), the specimens become less notch sensitive as the proportion of $\pm 45^{\circ}$ plies increases. For example, the compressive strength for the specimens with a circular hole is approximately $35 \%$ of the unnotched strength for the 0dom layup and $75 \%$ of the unnotched strength for the 45dom lay-up. Likewise, Soutis et al. (1993) reported that the presence of $\pm 45^{\circ}$ plies reduces the notch sensitivity of compressive specimens through more extensive damage.

In broad terms, lay-up affects notched strength and notch sensitivity through its effect on damage growth (Kortschot and Beaumont, 1990): a large extent of subcritical damage is usually accompanied by a high failure strength. This explains the trends in the observed failure envelopes, such as the curved profile of the regime of Mechanism B for all circular hole specimens, the overlapping of failure envelopes for both notch and circular hole 0dom specimens, and why for the 45dom lay-up, the regimes of Mechanism A for both notch geometries overlap whereas the regimes of Mechanism B do not. The effect of damage on strength also explains why in general, the strengths of the notch specimens are either slightly higher than or comparable to the strengths of the circular hole specimens for all lay-ups. Similar behaviours have been reported in the literature for tensile specimens (Eriksson and Aronsson, 1990; Carlsson et al., 1989; Lagace, 1986; Xu et al., 2014) and for shear specimens (Hollmann, 1991).

\section{Concluding remarks}

The effect of laminate lay-up upon the notched strength behaviour of CFRP has been investigated in this paper by varying the proportions of the $0^{\circ}$ plies and $\pm 45^{\circ}$ plies. Several laminate lay-ups were produced and tested under multi-axial loading. The investigation was split into two parts. The first phase employed the experimental protocol of Tan et al. (2015) to investigate the effect of laminate lay-up upon the multi-axial fracture behaviour of CFRP specimens. In the second phase, the FE strategy of Tan et al. (2016) was used to predict the multiaxial strength of specimens containing a notch or circular hole. This approach models each ply and each interface between plies. It remains a subject of future research to predict the strength of a thick laminate that contains too many layers for layer-by-layer resolution.

The experiments revealed that Mechanisms A, B and C, as previously observed in the quasi-isotropic lay-up (QI), were also observed in a wide range of lay-ups. However, the extent of damage, as well as the regime in which each damage mechanism is active, depends on the lay-up 
of the specimen. The FE model adequately predicted the failure envelopes and the notched strengths of the laminate lay-ups, including the sensitivity of strength to lay-up. The degree of subcritical damage for both notch geometries were also predicted to reasonable accuracy, particularly in the 0 and 90 plies. There exists reduced fidelity in the predictions of splits in the 45 plies and this is traced to the topology of the mesh. The mesh was aligned with the 0 and 90 fibre directions, and splits in these directions are not impeded by the mesh boundaries. In contrast, the mesh in the 45 plies did not align with the local fibre direction and consequently the prediction of splitting of these plies is less accurate. 
Table 1 HexPly ${ }^{\circledR}$ IM7/8552 lay-ups.

\begin{tabular}{|l|c|c|c|c|c|}
\hline \multirow{2}{*}{ Laminate type } & \multirow{2}{*}{ Abbreviation } & \multirow{2}{*}{ Lay-up } & \multicolumn{3}{|c|}{ Proportion of plies (\%) } \\
\cline { 4 - 6 } & & & $0^{\circ}$ & $\pm 45^{\circ}$ & $90^{\circ}$ \\
\hline Quasi-isotropic & QI & {$\left[(45 / 0 /-45 / 90)_{2}\right]_{\mathrm{s}}$} & 25 & 50 & 25 \\
\hline $0^{\circ}$ ply-dominated & 0dom & $\left(04 / \pm 45 / 0_{2}\right)_{\mathrm{S}}$ & 75 & 25 & 0 \\
\hline $\pm 45^{\circ}$ ply-dominated & $45 \mathrm{dom}$ & $( \pm 45 / 0 / \pm 45 / 90 / \pm 45)_{\mathrm{S}}$ & 12.5 & 75 & 12.5 \\
\hline Cross-ply & CP & {$\left[(0 / 90)_{3} / 0 / 90\right]_{\mathrm{s}}$} & 53.3 & 0 & 46.7 \\
\hline
\end{tabular}

Table 2: Material parameters for the ply model

\begin{tabular}{|c|c|}
\hline$E_{1}(\mathrm{GPa})$ & 162 \\
\hline$E_{2}(\mathrm{GPa})$ & 8.96 \\
\hline$G(\mathrm{GPa})$ & 4.49 \\
\hline 21 & 0.316 \\
\hline$X^{T}(\mathrm{MPa})$ & 2560 \\
\hline$X^{c}(\mathrm{MPa})$ & 500 \\
\hline$Y^{T}(\mathrm{MPa})$ & 64 \\
\hline$Y^{c}(\mathrm{MPa})$ & 286 \\
\hline$J_{f}^{t}\left(\mathrm{~kJ} / \mathrm{m}^{2}\right)$ & 81.5 \\
\hline$J_{f}^{c}\left(\mathrm{~kJ} / \mathrm{m}^{2}\right)$ & 106 \\
\hline$J_{m}^{t}\left(\mathrm{~kJ} / \mathrm{m}^{2}\right)$ & 277 \\
\hline$J_{m}^{c}\left(\mathrm{~kJ} / \mathrm{m}^{2}\right)$ & 788 \\
\hline
\end{tabular}

Table 3: Parameters for the cohesive delamination model

\begin{tabular}{|c|c|}
\hline$k_{n}$ & $7.612 \times 10^{5} \mathrm{GPa} \mathrm{m}^{-1}$ \\
\hline$k_{s}$ & $1.37 \times 10^{5} \mathrm{GPa} \mathrm{m}^{-1}$ \\
\hline$T_{n}$ & $76 \mathrm{MPa}$ \\
\hline$T_{s}$ & $137 \mathrm{MPa}$ \\
\hline$G_{c}^{n}$ & $208 \mathrm{~J} \mathrm{~m}^{-2}$ \\
\hline$G_{c}^{s}$ & $1334 \mathrm{~J} \mathrm{~m}^{-2}$ \\
\hline
\end{tabular}




\section{References}

Awerbuch J., Madhukar M.S., 1985. Notched Strength of Composite Laminates: Predictions and Experiments--A Review. J. Reinf. Plast. Compos. 4, 3-159.

Berbinau, P., Soutis, C., Goutas, P., Curtis, P.T., 1999. Effect of off-axis ply orientation on 0-fibre microbuckling. Compos. Part A Appl. 30, 1197-1207.

Bishop, S.M., 1985. The mechanical performance and impact behaviour of carbon-fibre reinforced PEEK. Compos. Struct. 3, 295-318.

Camanho, P.P., Davila, C.G., 2002. Mixed-Mode Decohesion Finite Elements for the Simulation of Delamination in Composite Materials. NASA/TM-2002-211737, 1-37.

Carlsson L.A., Aronsson C.G., Bäcklund J., 1989. Notch sensitivity of thermoset and thermoplastic laminates loaded in tension. J. Mater. Sci. 24, 1670-1682.

Chow C.L., Xian X.J., Lam J., 1990. Experimental investigation and modelling of damage evolution/propagation in carbon/epoxy laminated composites. Compos. Sci. Technol. 39, 159-184.

Eriksson I., Aronsson C-G., 1990. Strength of Tensile Loaded Graphite/Epoxy Laminates Containing Cracks, Open and Filled Holes. J. Compos. Mater. 24, 456-482.

Fleck, N.A., 1997. Compressive failure of fibre composites. Adv. Appl. Mech. 33, 43-117.

Garg, A.C., 1986. The fracture mechanics of some graphite fibre-reinforced epoxy laminates, Part 1: quasi-isotropic laminates. Composites 17, 141-149.

Gning, P.B., Delsart, D., Mortier, J.M., Coutellier, D., 2010. Through-thickness strength measurements using Arcan's method. Compos. Part B Eng. 41, 308-316.

González, E.V., Maimf, P., Camanho, P.P., Turon, A., and Mayugo, J.A., 2012. Simulation of dropweight impact and compression after impact tests on composite laminates. Compos Struct 94, 3364-3378.

Green, B.G., Wisnom, M.R., Hallett, S.R., 2007. An experimental investigation into the tensile strength scaling of notched composites. Compos. Part A Appl. Sci. Manuf. 38, 867-878. 
Hallett S.R., Green, B.G., Jiang, W.G., Wisnom, M.R., 2009. An experimental and numerical investigation into the damage mechanisms in notched composites. Compos. Part A Appl. Sci. Manuf. 40, 613-624.

Hashin, Z., 1980. Failure Criteria for Unidirectional Fiber Composites, J Appl Mech. 47, 329-334.

Hashin, Z., Rotem, A.A., 1973. Fatigue Criterion for Fiber-Reinforced Materials. J. Compos. Mater. 7, 448-464.

Hollmann, K., 1991. In-plane shear failure analysis of notched composites. Compos. Sci. Technol. 41, 257-285.

Kortschot, M.T., Beaumont, P.W.R., 1990. Damage mechanics of composite materials: 1 Measurements of damage and strength. Compos. Sci. Technol. 39, 289-301.

Kortschot, M.T., Beaumont, P.W.R., 1991. Damage mechanics of composite materials. IV: The effect of lay-up on damage growth and notched strength. Compos. Sci. Technol. 40, 167-179.

Laffan, M.J., Pinho, S.T., Robinson, P., Iannucci, L., 2010. Measurement of the in situ ply fracture toughness associated with mode I fibre tensile failure in FRP. Part II: Size and lay-up effects. Compos. Sci. Technol. 70, 614-621.

Lagace, PA., 1986. Notch sensitivity of graphite/epoxy fabric laminates. Compos. Sci. Technol. 26, 95-117.

Li, X., Hallett, S.R., Wisnom, M.R., 2012. Numerical investigation of progressive damage and the effect of layup in overheight compact tension tests. Compos. Part A Appl. Sci. Manuf. 43, 21372150.

Lopes, C.S., Sadaba, S., Gonzalez, C., Llorca, J. and Camanho, P.P., 2016. Physically-sound simulation of low-velocity impact on fiber reinforced laminates. Int. J. Impact Engng. 92, 3-17.

Matzenmiller, A., Lubliner, J., Taylor, R.L., 1995. A Constitutive Model for Anisotropic Damage in Fiber-Composites. Mech. Mater. 20, 125-152.

O’Higgins RM, McCarthy M.A., McCarthy C.T. 2008. Comparison of open hole tension characteristics of high strength glass and carbon fibre-reinforced composite materials. Compos. Sci. Technol. 68, 2770-2778. 
Scott, A.E., Mavrogordato, M., Wright, P., Sinclair, I., Spearing, S.M., 2011. In situ fibre fracture measurement in carbon-epoxy laminates using high resolution computed tomography. Compos. Sci. Technol., 71, 1471-1477.

Sket, F., Seltzer, R., Molina-Aldareguia, J.M., Gonzalez, C., Llorca, J., 2012. Determination of damage micromechanisms and fracture resistance of glass fiber/epoxy cross-ply laminate by means of X-ray computed microtomography. Compos. Sci. Technol. 72, 350-359.

Sivashanker, S., Fleck, N.A., Sutcliffe, M.P.F., 1996. Microbuckle propagation in a unidirectional carbon fibe-epoxy matrix composite. Acta Mater. 44, 2581-2590.

Soutis, C., 1994. Damage tolerance of open-hole CFRP laminates loaded in compression. Compos. Eng. 4, 317-327.

Soutis, C., Curtis, P.T., Fleck, N.A., 1993. Compressive failure of notched carbon fibre composites. Proc. R. Soc. London Ser. A Math. Phys. Sci. 440, 241-256.

Tan, J.L.Y., Deshpande, V.S., Fleck, N.A., 2015. Failure mechanisms of a notched CFRP laminate under multi-axial loading. Composites Part A: Applied Science and Manufacturing 77, 56-66.

Tan, J.L.Y., Deshpande, V.S., Fleck, N.A., 2016. Prediction of strength and damage evolution in notched CFRP laminates under multi-axial loading. Phil. Trans. R. Soc. A 20150273, 1-17.

Wang, J., Callus, P.J., Bannister, M.K., 2004. Experimental and numerical investigation of the tension and compression strength of un-notched and notched quasi-isotropic laminates. Compos. Struct. 64, 297-306.

Xu, X., Wisnom, M.R., Mahadik, Y., Hallett, S.R., 2014. An Experimental Investigation into Size Effects in Quasi-isotropic Carbon/Epoxy Laminates with Sharp and Blunt Notches. Compos. Sci. Technol.

Zhou, G., Green, E.R., Morrison, C., 1995. In-plane and interlaminar shear properties of carbon/epoxy laminates. Compos. Sci. Technol. 55, 187-193. 


\section{Figure captions}

Fig. 1. (a) Specimen geometry. All dimensions are in $\mathrm{mm}$. Notch length is $a=6.25 \mathrm{~mm}$, and circular hole diameter is $a=6 \mathrm{~mm}$. (b) modified Arcan geometry.

Fig. 2. The dominant failure mechanisms as a function of loading direction. Here, $l_{s}$ is the split length, $l_{f}$ the crack length of failed $0^{\circ}$ fibres in tension and $l_{m}$ is the extent of microbuckling.

Fig. 3. Measured failure surface for selected lay-ups. QI denotes quasi-isotropic, 45dom denotes $45^{\circ}$ dominated, and 0dom denotes $0^{\circ}$ dominated. (a) notch geometry; (b) circular hole.

Fig. 4. Measured and predicted tensile strength for $\varphi=0^{\circ}$ as a function of the volume fraction of $0^{\circ}$ plies. (a) notch and (b) circular hole.

Fig. 5. Measured and predicted tensile strength for $\varphi=90^{\circ}$ as a function of the volume fraction of $\pm 45^{\circ}$ plies. (a) notch and (b) circular hole.

Fig. 6. Measured and predicted compressive strength for $\varphi=180^{\circ}$ as a function of the volume fraction of $0^{\circ}$ plies. (a) notch and (b) circular hole.

Fig. 7. (a) Penetrant-enhanced X-ray CT-scans of the $0^{\circ}$ ply at $90 \%$ tensile failure load $\left(\varphi=0^{\circ}\right)$ for lay-ups (i) $\pm 45^{\circ}$ dominated, $45 \mathrm{dom}$, (ii) quasi-isotropic, QI, (iii) cross-ply, CP, and (iv) $0^{\circ}$ dominated, 0dom; (b) $0^{\circ}$ split length $l_{s}$ and crack length $l_{f}$ of failed $0^{\circ}$ fibres as a function of the proportion of $0^{\circ}$ plies; (c) Penetrant-enhanced X-ray CT-scans of the $0^{\circ}$ ply orientation at $90 \%$ compressive failure load $\left(\varphi=180^{\circ}\right)$ for the lay-ups (i) $0^{\circ}$ dominated, Odom, (ii) quasi-isotropic, QI, and (iii) $\pm 45^{\circ}$ dominated, $45 \mathrm{dom}$; (d) $-45^{\circ}$ split length $l_{s}$ and extent of microbuckled zone $l_{m}$ as a function of the proportion of $\pm 0^{\circ}$ plies.

Fig. 8. Penetrant-enhanced X-ray CT-scans of the $-45^{\circ}$ ply orientation at $90 \%$ shear failure load $\left(\varphi=90^{\circ}\right)$ for lay-ups (i) $0^{\circ}$ dominated, Odom, (ii) quasi-isotropic, QI, and (iii) $\pm 45^{\circ}$ dominated, 45dom.

Fig. 9. Predicted and measured failure envelopes for specimens of lay-up 0dom (a) notch and (b) circular hole, and for specimens of lay-up 45dom (c) notch and (d) circular hole.

Fig. 10. Predicted versus measured damage state in $0^{\circ}$ plies in $45 \mathrm{dom}$, 0dom and CP layups at $90 \%$ failure load (pure tension, $\varphi=0^{\circ}$ ). 
Fig. 11. Predicted versus measured damage state in $-45^{\circ}$ plies in the 0 dom and 45 dom layups at $90 \%$ failure load (pure shear, $\varphi=90^{\circ}$ ).

Fig. 12. Predicted versus measured damage state in $0^{\circ}$ plies in the $45 \mathrm{dom}, 0 \mathrm{dom}$ and CP lay-ups at $90 \%$ failure load (pure compression, $\varphi=180^{\circ}$ ).

Fig. 13. Predicted versus measured damage at $90 \%$ failure load in selected circular hole specimens. For tension $\left(\varphi=0^{\circ}\right.$, mechanism A), damage is shown in the $0^{\circ}$ plies for the 0dom laminate; for shear $\left(\varphi=90^{\circ}\right.$, mechanism B), damage is shown in the $-45^{\circ}$ plies the 45 dom laminate; and for compression $\left(\varphi=180^{\circ}\right.$, mechanism $\left.C\right)$, damage is shown in the $0^{\circ}$ plies damage for the $\mathrm{CP}$ laminate. 


\section{Figures}

(a)

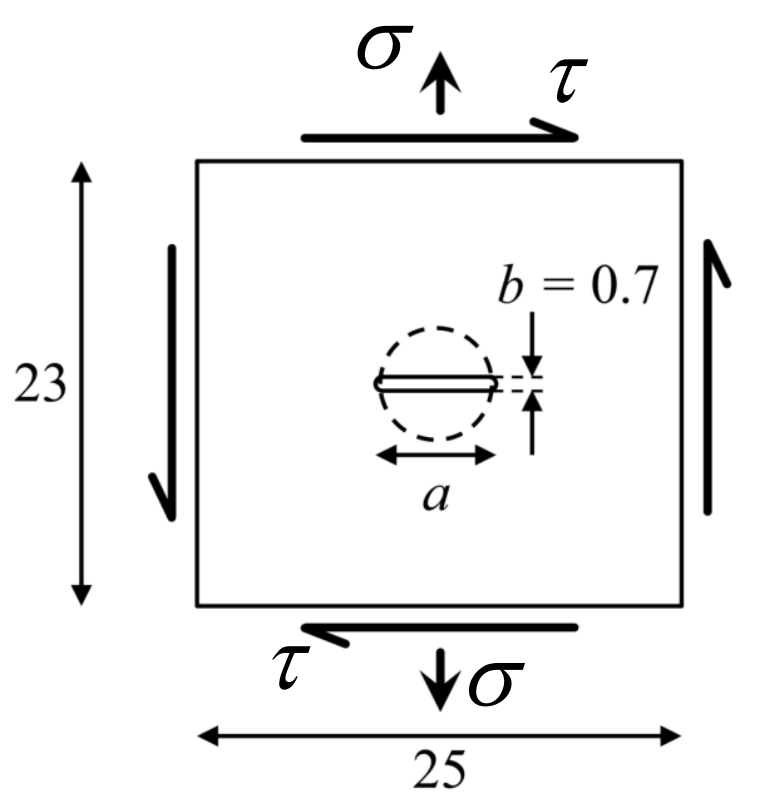

(b)

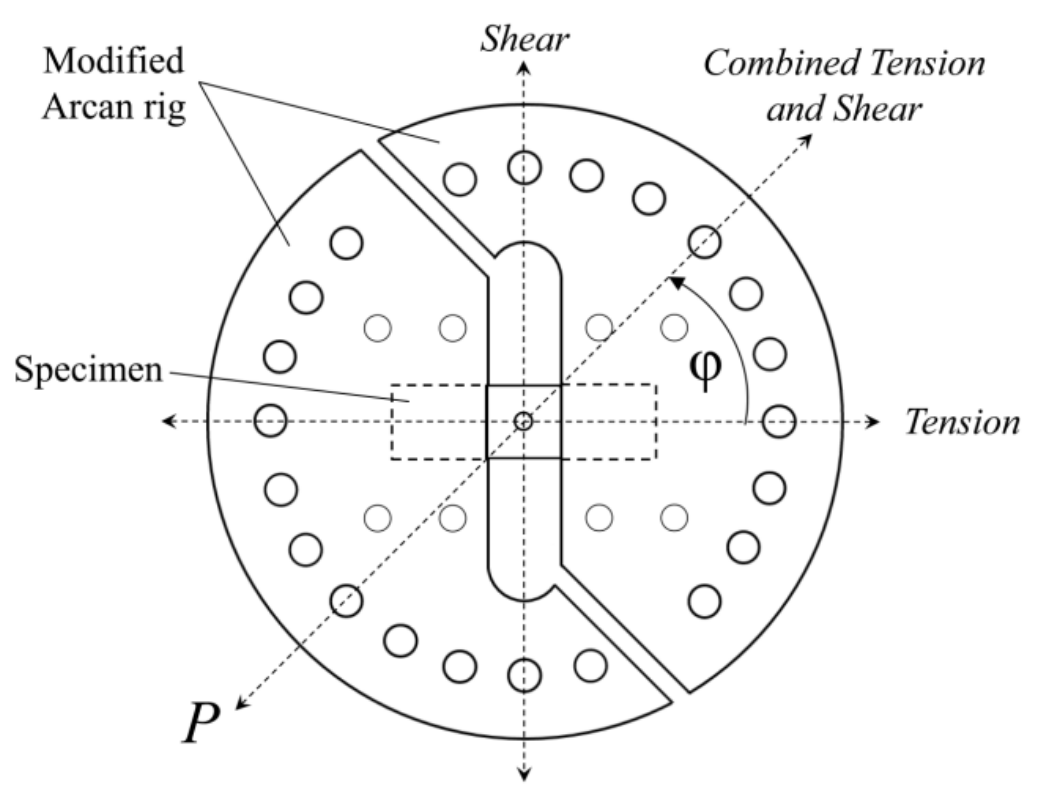

Fig. 1. (a) Specimen geometry. All dimensions are in $\mathrm{mm}$. Notch length is $a=6.25 \mathrm{~mm}$, and circular hole diameter is $a=6 \mathrm{~mm}$. (b) modified Arcan geometry. 


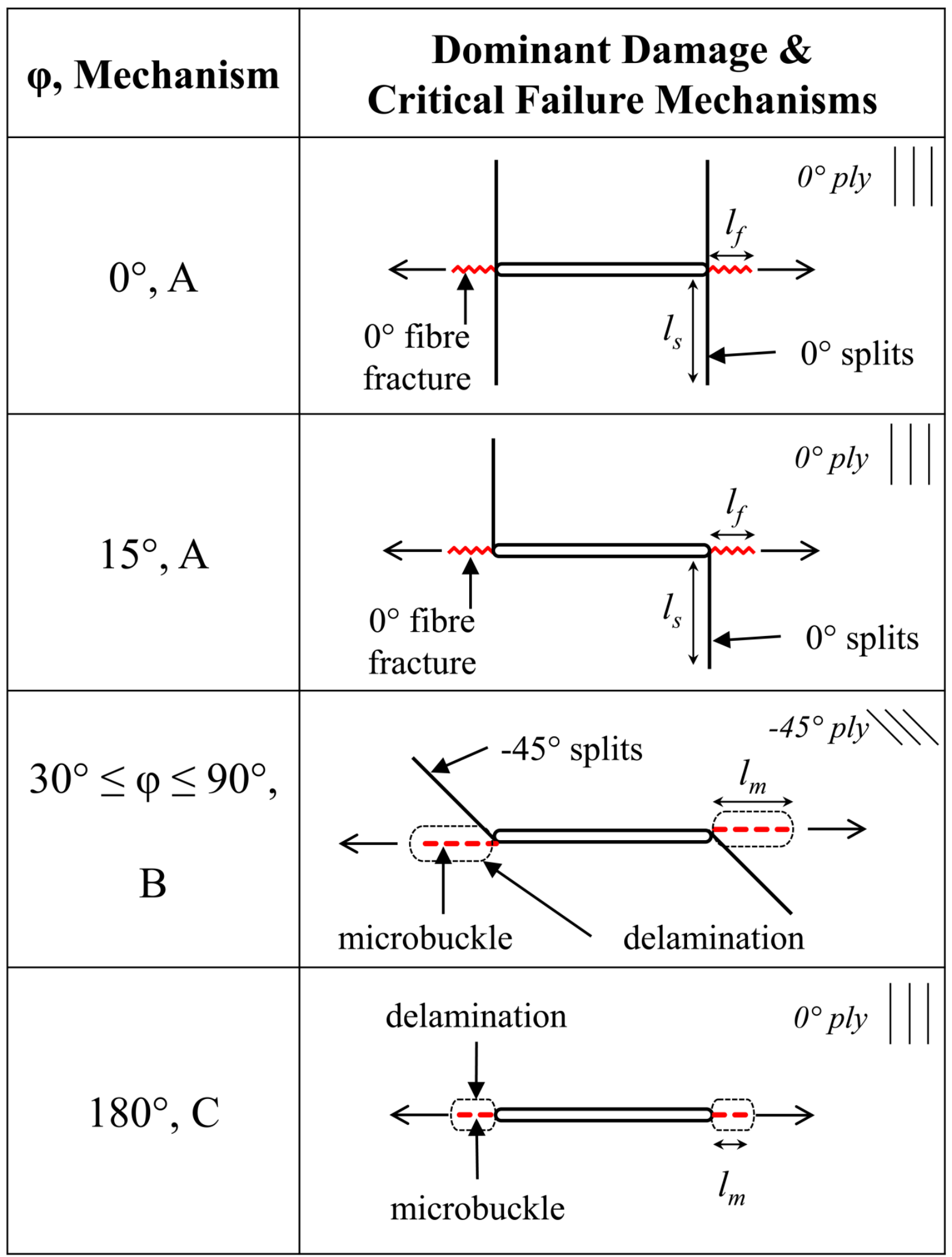

Fig. 2. The dominant failure mechanisms as a function of loading direction. Here, $l_{s}$ is the split length, $l_{f}$ the crack length of failed $0^{\circ}$ fibres in tension and $l_{m}$ is the extent of microbuckling. 
(a)

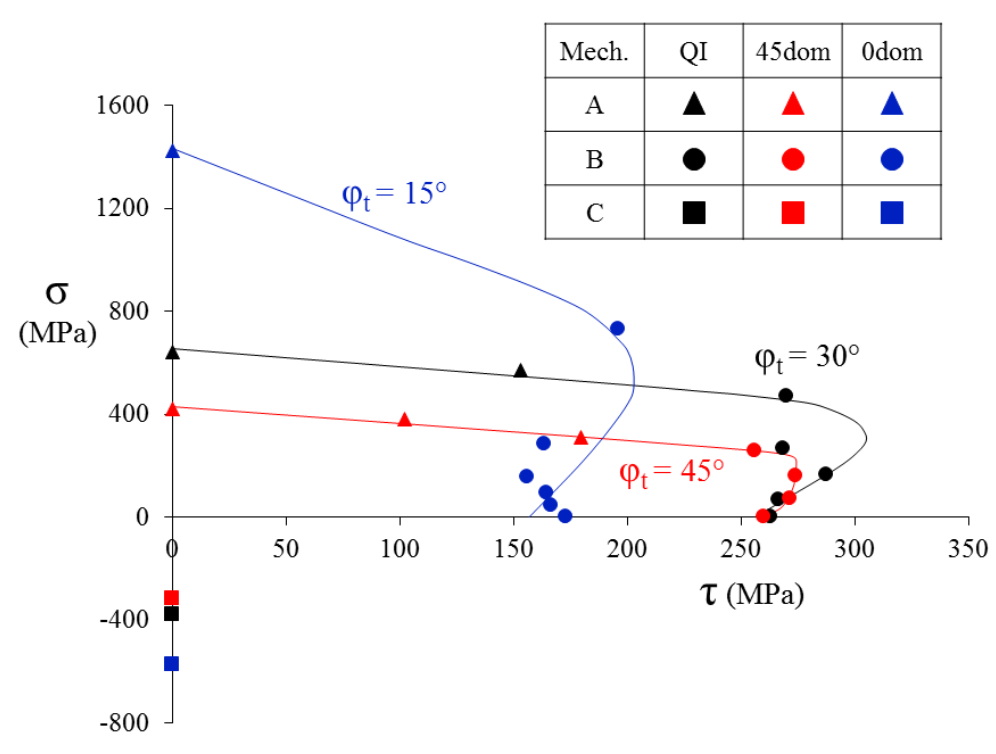

(b)

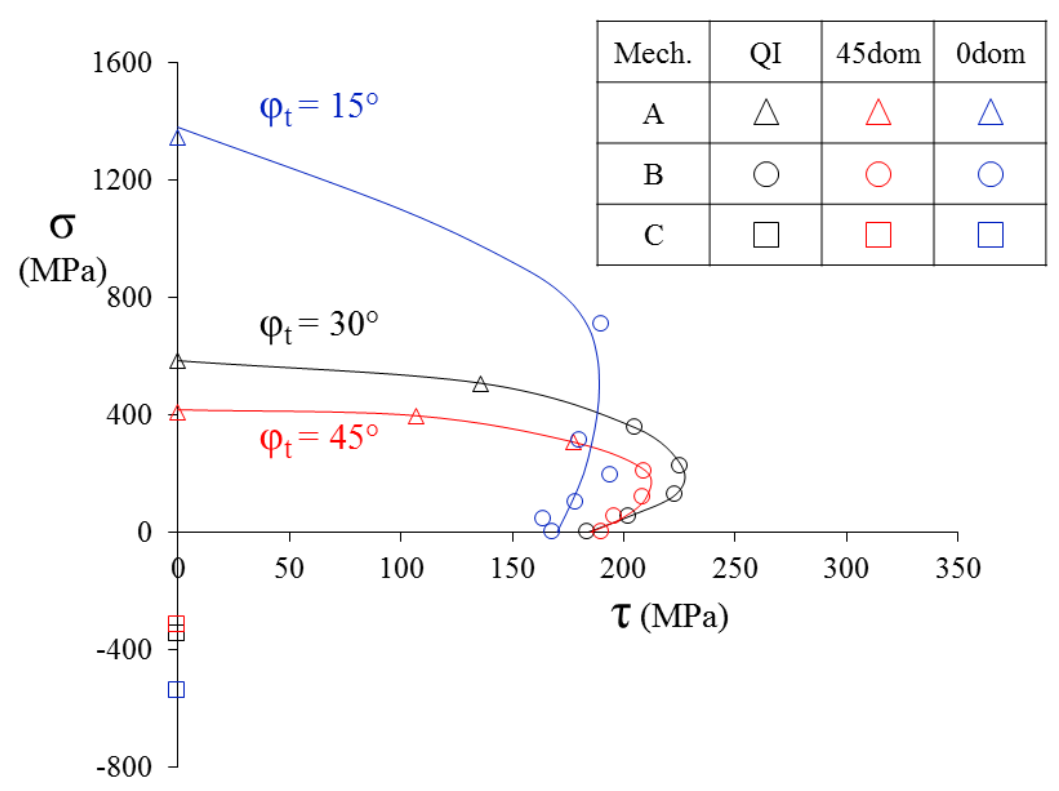

Fig. 3. Measured failure surface for selected lay-ups. QI denotes quasi-isotropic, 45dom denotes $45^{\circ}$ dominated, and 0dom denotes $0^{\circ}$ dominated. (a) notch geometry; (b) circular hole. 
(a)

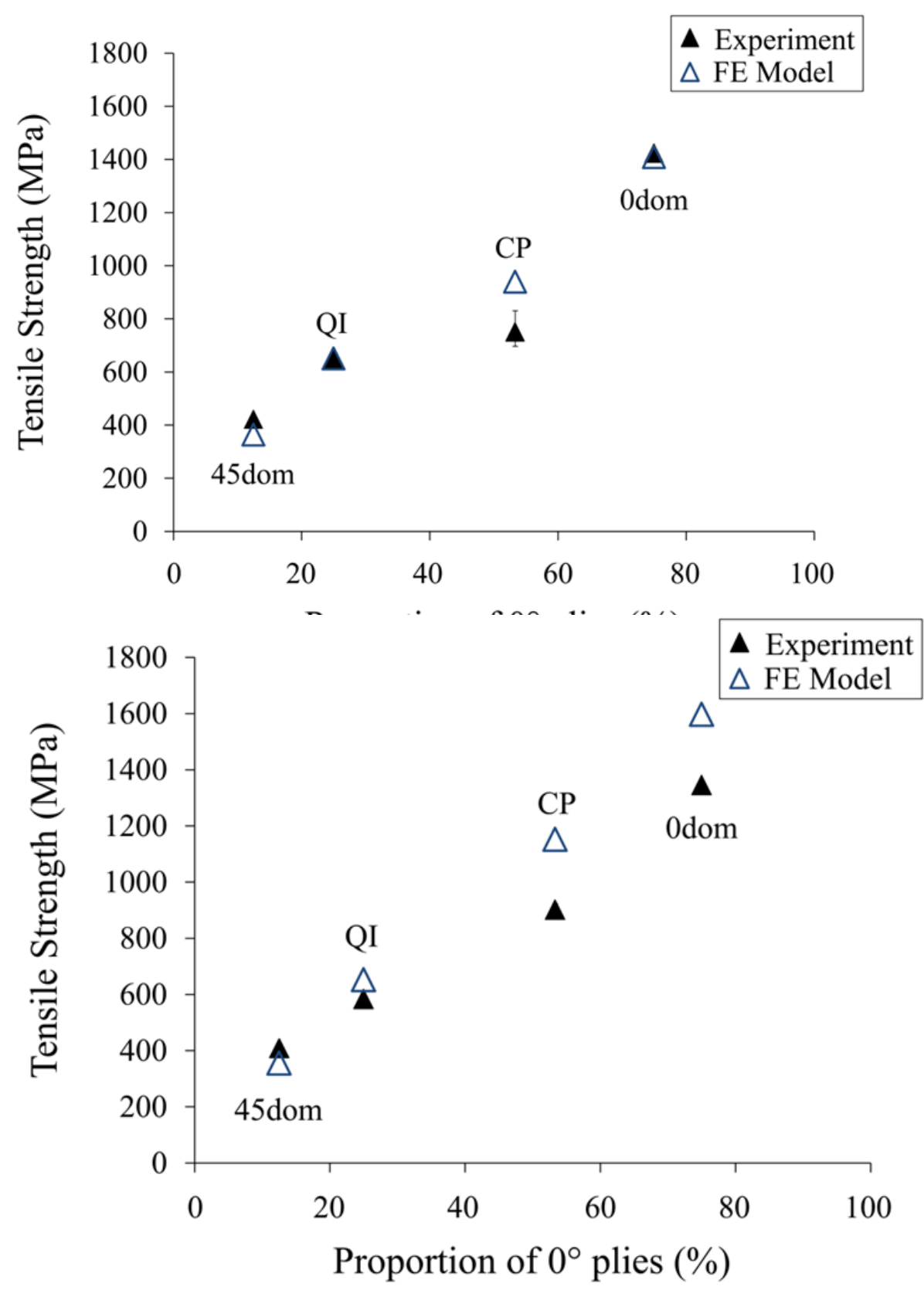

Fig. 4. Measured and predicted tensile strength for $\varphi=0^{\circ}$ as a function of the volume fraction of $0^{\circ}$ plies. (a) notch and (b) circular hole. 
(a)

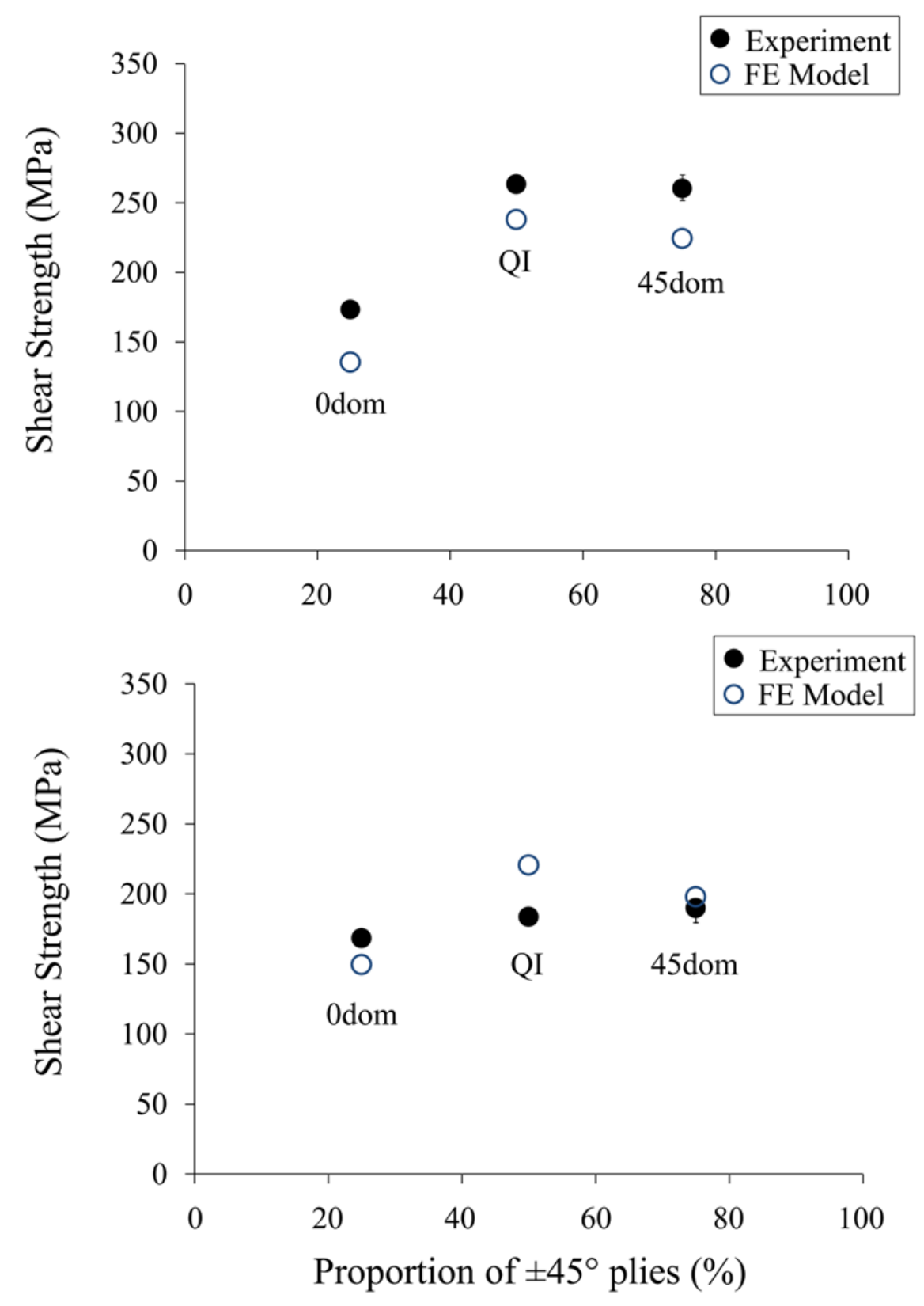

Fig. 5. Measured and predicted tensile strength for $\varphi=90^{\circ}$ as a function of the volume fraction of $\pm 45^{\circ}$ plies. (a) notch and (b) circular hole. 
(a)

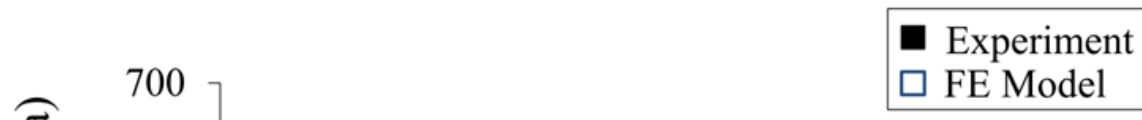

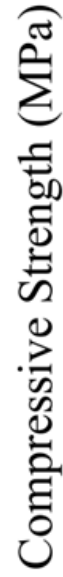

0dom

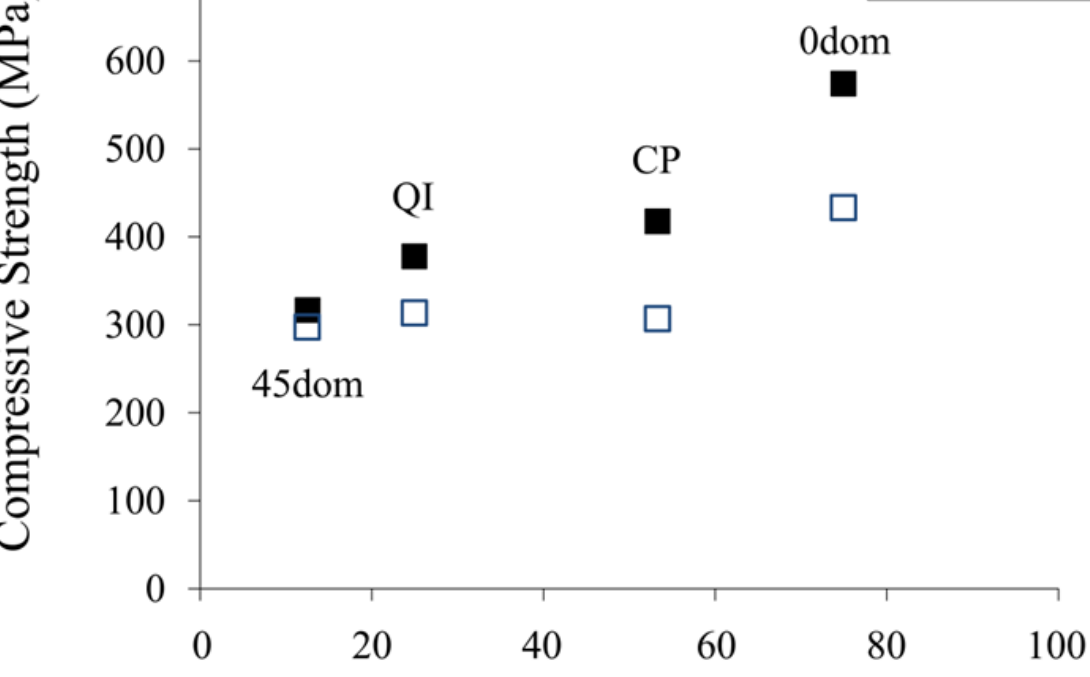

(b)

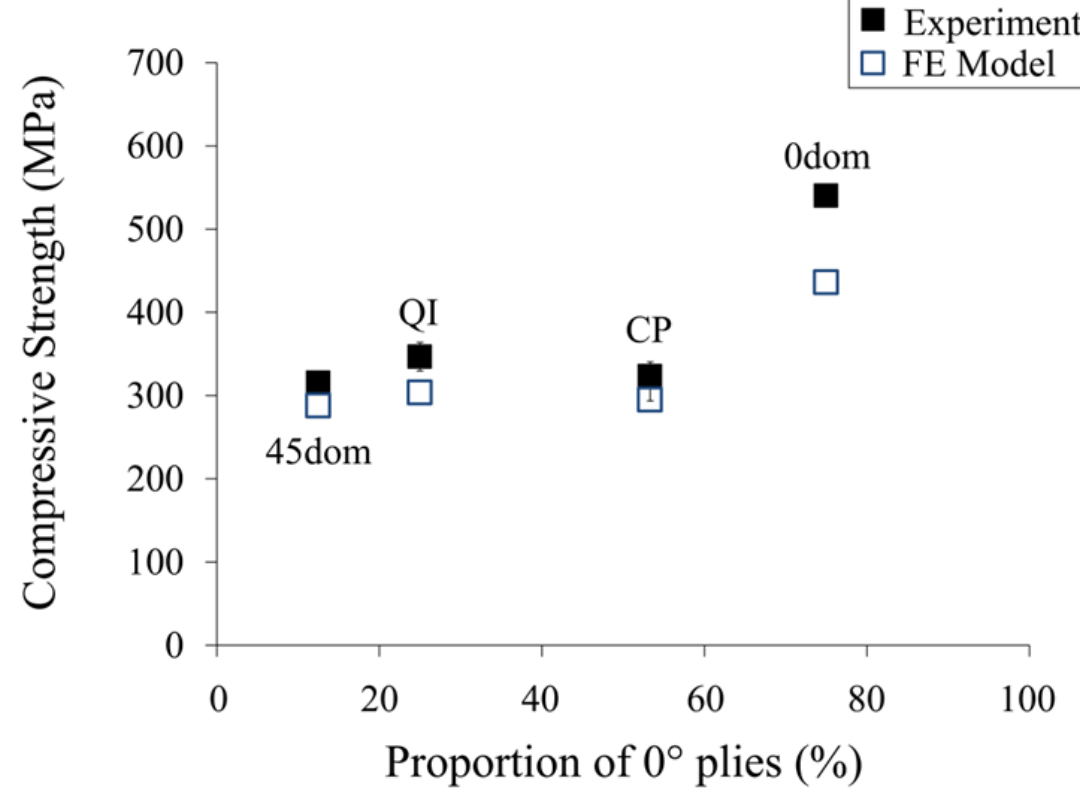

Fig. 6. Measured and predicted compressive strength for $\varphi=180^{\circ}$ as a function of the volume fraction of $0^{\circ}$ plies. (a) notch and (b) circular hole. 
(a)

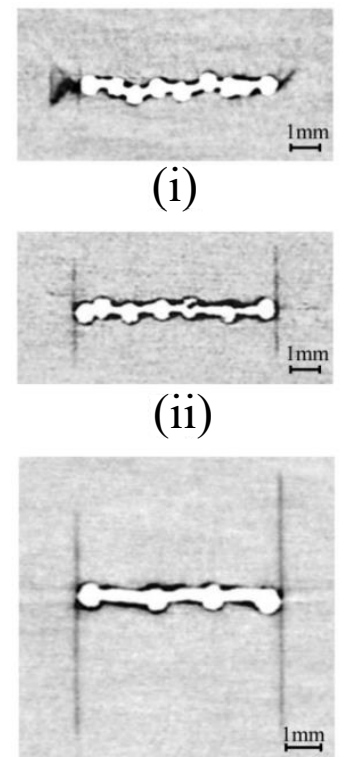

(iii)

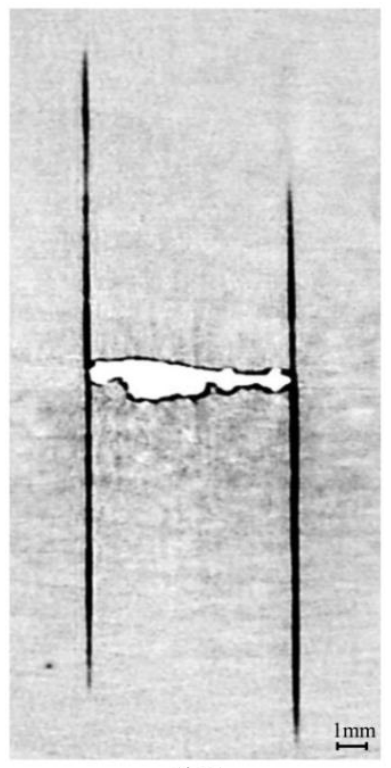

(iv)

(b)

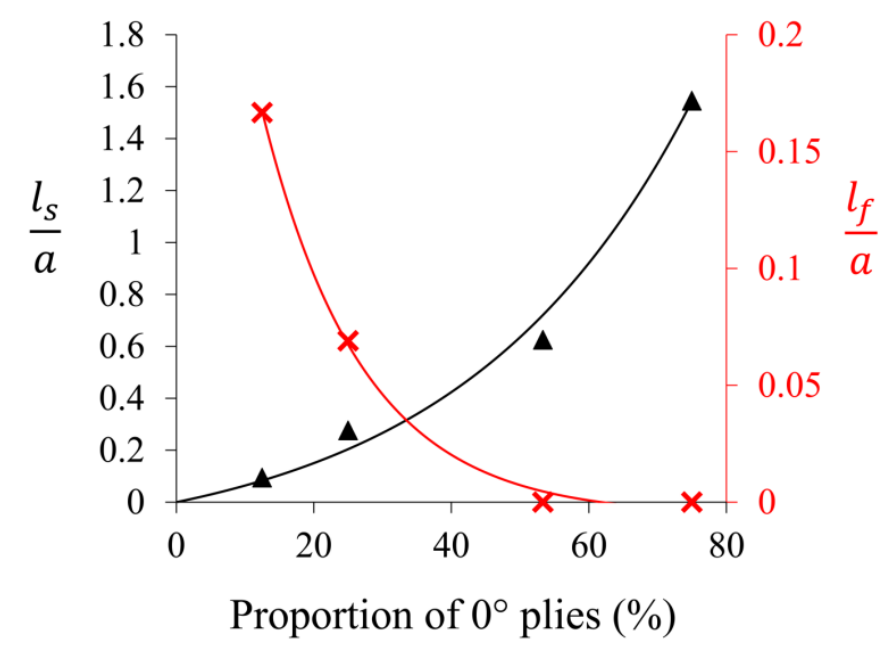

(c)

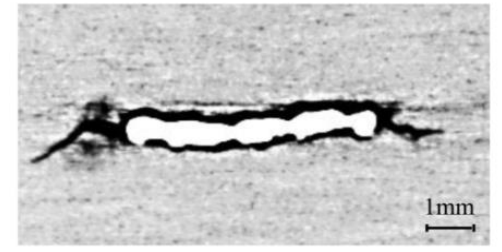

(i)

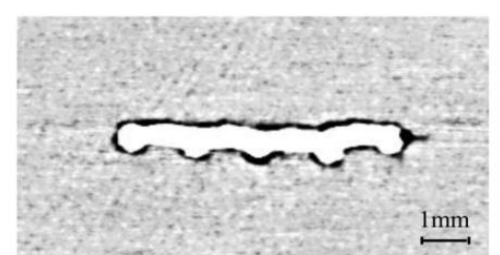

(iii

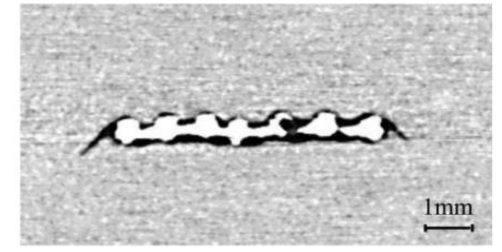

(ii)

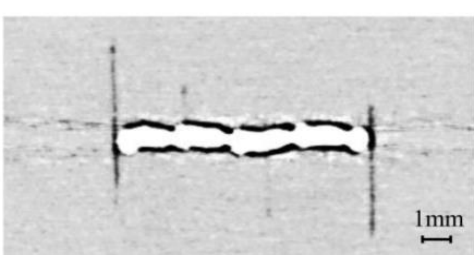

(iv) 
(d)

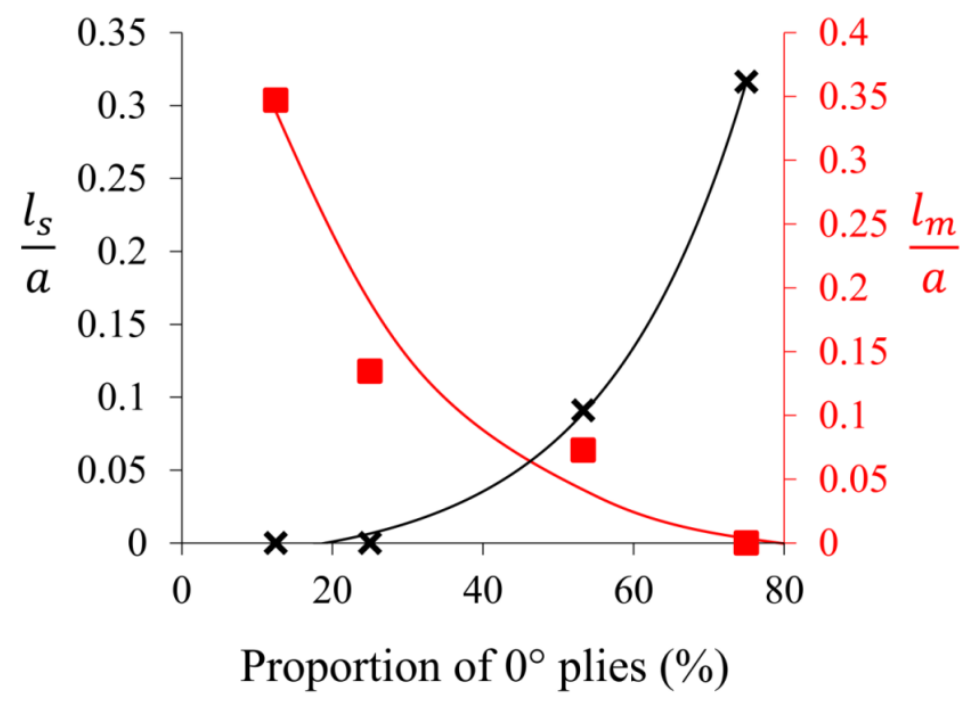

Fig. 7. (a) Penetrant-enhanced X-ray CT-scans of the $0^{\circ}$ ply at $90 \%$ tensile failure load $\left(\varphi=0^{\circ}\right)$ for lay-ups (i) $\pm 45^{\circ}$ dominated, 45dom, (ii) quasi-isotropic, QI, (iii) cross-ply, CP, and (iv) $0^{\circ}$ dominated, 0dom; (b) $0^{\circ}$ split length $l_{s}$ and crack length $l_{f}$ of failed $0^{\circ}$ fibres as a function of the proportion of $0^{\circ}$ plies; (c) Penetrant-enhanced X-ray CT-scans of the $0^{\circ}$ ply orientation at $90 \%$ compressive failure load $\left(\varphi=180^{\circ}\right)$ for the lay-ups (i) $0^{\circ}$ dominated, Odom, (ii) quasi-isotropic, QI, and (iii) $\pm 45^{\circ}$ dominated, $45 \mathrm{dom}$; (d) $-45^{\circ}$ split length $l_{s}$ and extent of microbuckled zone $l_{m}$ as a function of the proportion of $\pm 0^{\circ}$ plies. 


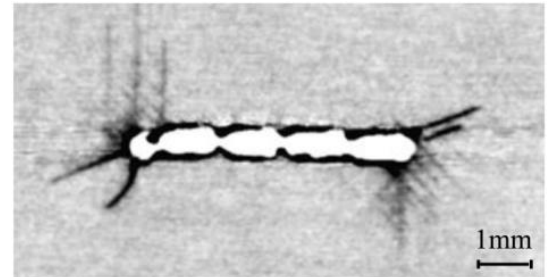

(i)

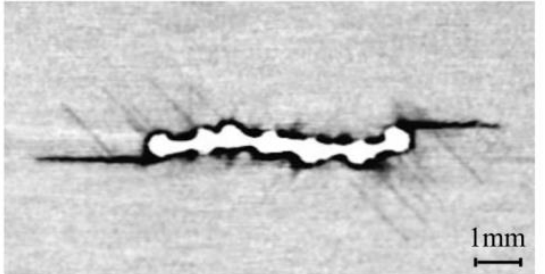

(ii)

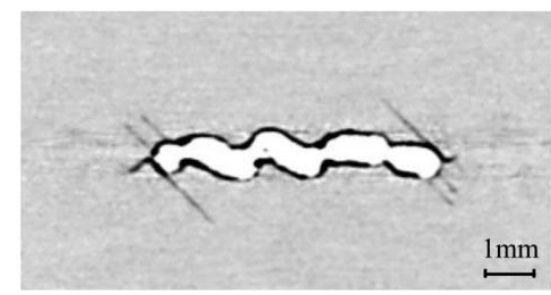

(iii)

Fig. 8. Penetrant-enhanced X-ray CT-scans of the $-45^{\circ}$ ply orientation at $90 \%$ shear failure load $\left(\varphi=90^{\circ}\right)$ for lay-ups (i) $0^{\circ}$ dominated, Odom, (ii) quasi-isotropic, QI, and (iii) $\pm 45^{\circ}$ dominated, $45 \mathrm{dom}$. 


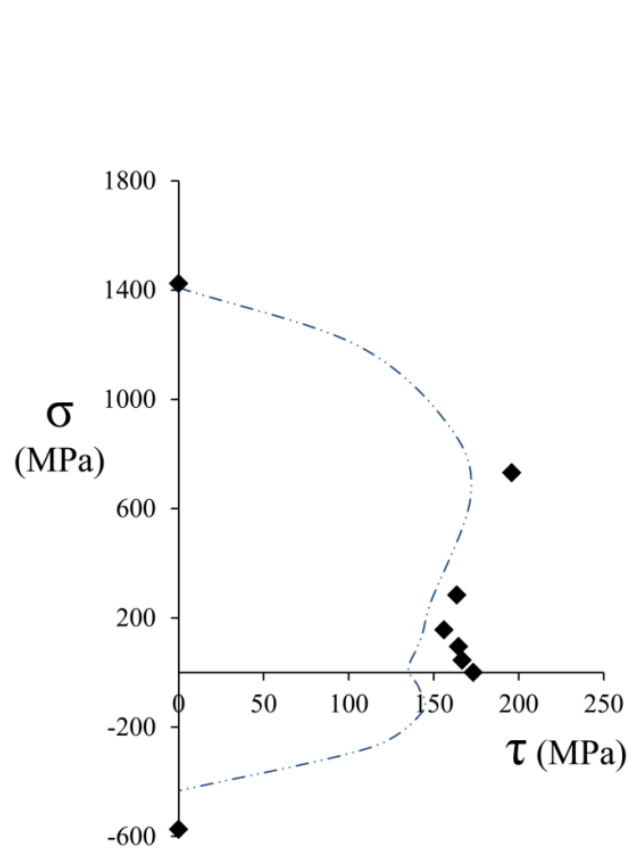

(a)

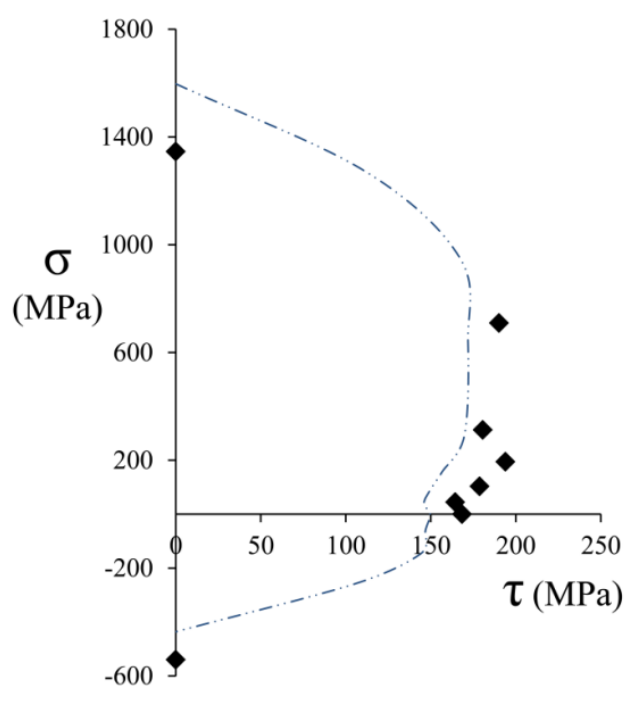

(b)

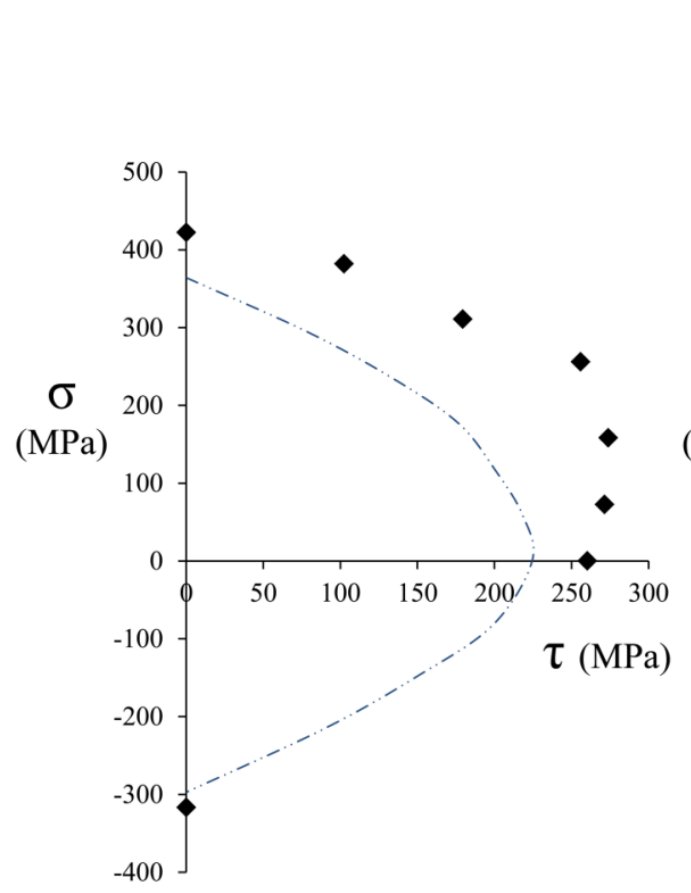

(c)

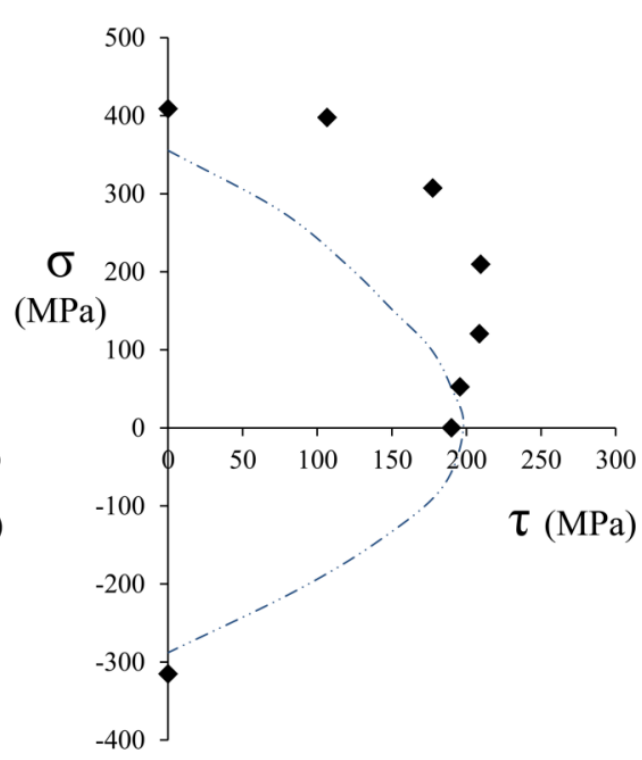

(d)

Fig. 9. Predicted and measured failure envelopes for specimens of lay-up 0dom (a) notch and (b) circular hole, and for specimens of lay-up 45dom (c) notch and (d) circular hole. 


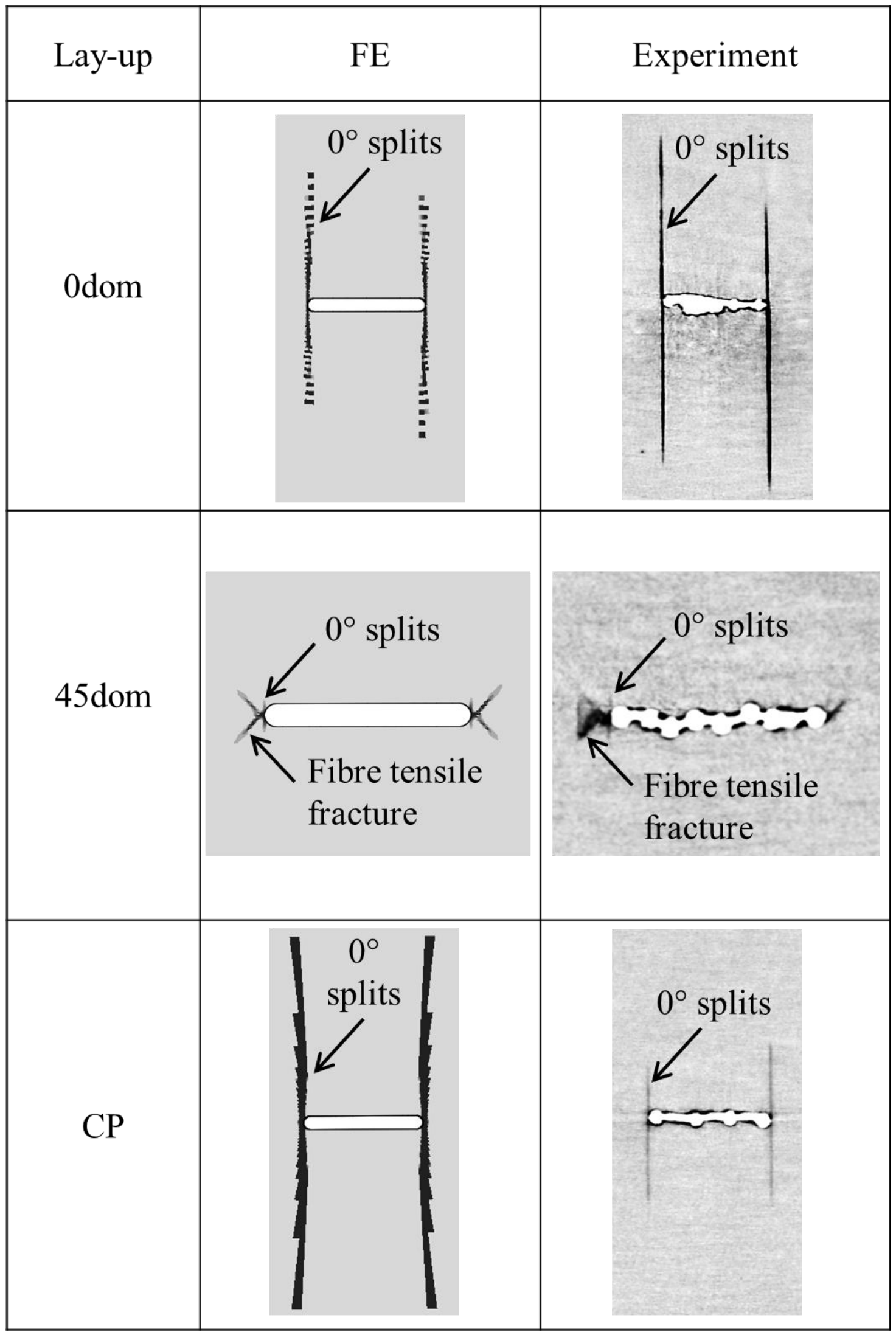

Fig. 10. Predicted versus measured damage state in $0^{\circ}$ plies in $45 \mathrm{dom}$, 0dom and CP layups at $90 \%$ failure load (pure tension, $\varphi=0^{\circ}$ ). 


\begin{tabular}{|c|c|c|}
\hline Lay-up & FE & Experiment \\
\hline 0dom & Fibre compressive failure & Microbuckling \\
\hline $45 \mathrm{dom}$ & Fibre compressive failure & Microbuckling \\
\hline
\end{tabular}

Fig. 11. Predicted versus measured damage state in $-45^{\circ}$ plies in the 0 dom and 45 dom layups at $90 \%$ failure load (pure shear, $\varphi=90^{\circ}$ ). 


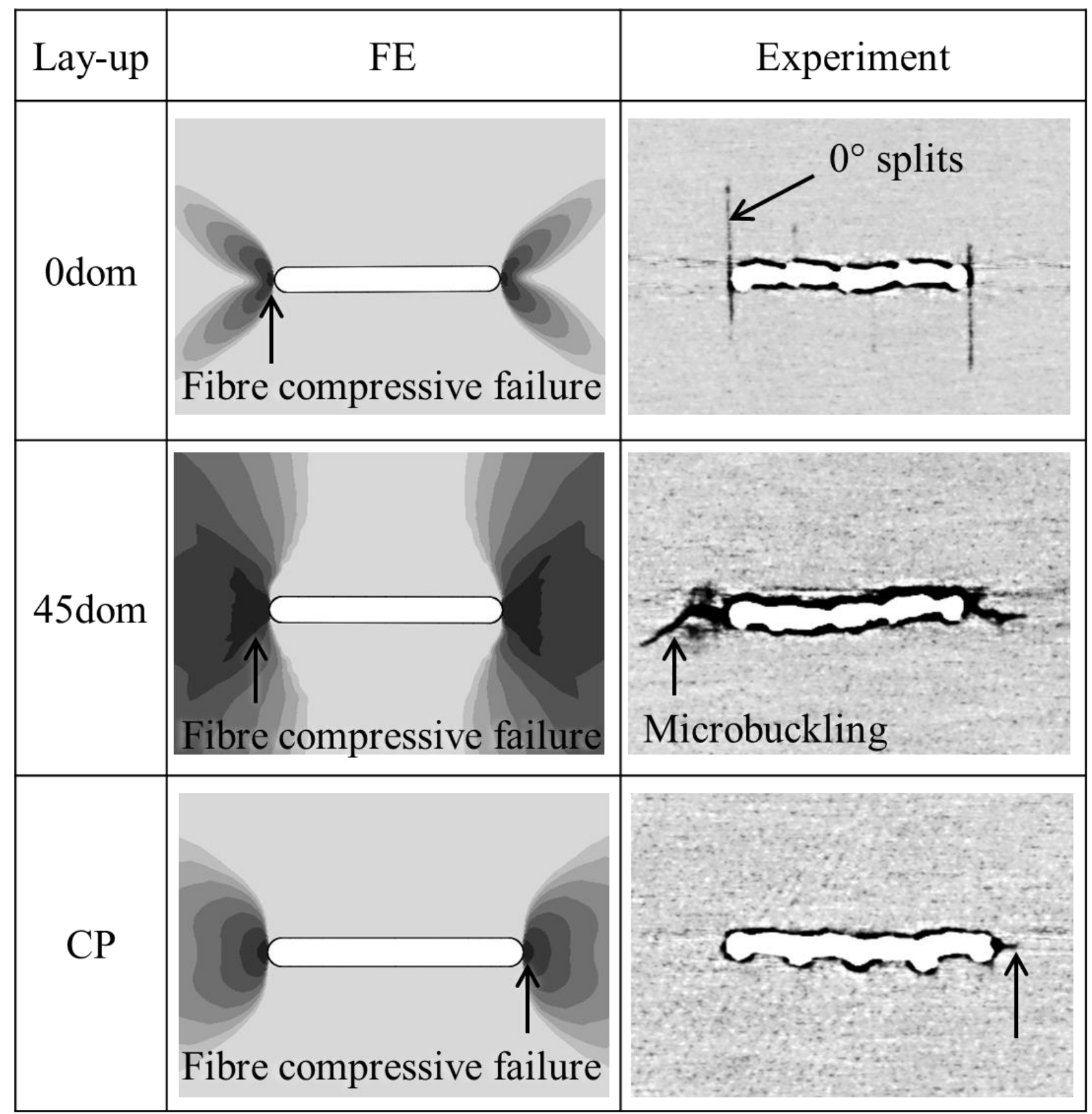

Fig. 12. Predicted versus measured damage state in $0^{\circ}$ plies in the $45 \mathrm{dom}, 0 \mathrm{dom}$ and CP lay-ups at $90 \%$ failure load (pure compression, $\varphi=180^{\circ}$ ). 


\begin{tabular}{|c|c|c|}
\hline $\begin{array}{c}\text { Lay-up } \\
(\varphi)\end{array}$ & FE & Experiment \\
\hline $\begin{array}{c}\left(\varphi=0^{\circ}\right) \\
(\varphi)\end{array}$ & $\begin{array}{c}\text { Fibre compressive } \\
\text { failure }\end{array}$ \\
\hline $\begin{array}{c}\text { CP dom } \\
\left(\varphi=90^{\circ}\right)\end{array}$
\end{tabular}

Fig. 13. Predicted versus measured damage at $90 \%$ failure load in selected circular hole specimens. For tension $\left(\varphi=0^{\circ}\right.$, mechanism A), damage is shown in the $0^{\circ}$ plies for the Odom laminate; for shear $\left(\varphi=90^{\circ}\right.$, mechanism B), damage is shown in the $-45^{\circ}$ plies the $45 \mathrm{dom}$ laminate; and for compression $\left(\varphi=180^{\circ}\right.$, mechanism $\left.\mathrm{C}\right)$, damage is shown in the $0^{\circ}$ plies damage for the $\mathrm{CP}$ laminate. 